\title{
Deuterated N2Py2 Ligands: Building More Robust Non-Heme Iron Oxidation Catalysts
}

\author{
Jianming Chen and Robertus J. M. Klein Gebbink*(1) \\ Organic Chemistry and Catalysis, Debye Institute for Nanomaterials Science, Utrecht University, Universiteitsweg 99,3584 CG \\ Utrecht, The Netherlands
}

\section{Supporting Information}

ABSTRACT: $\mathrm{Fe}(\mathrm{N} 2 \mathrm{Py} 2) / \mathrm{H}_{2} \mathrm{O}_{2} / \mathrm{AcOH}$ catalytic systems provide powerful tools for efficient $\mathrm{C}-\mathrm{H}$ and $\mathrm{C}=\mathrm{C}$ bond oxidations (N2Py2 = bis-alkylamine-bis-pyridine ligand). Yet, the stability of these catalysts under the oxidizing conditions still remains a problem. The generally accepted catalyst decomposition pathway of $\mathrm{Fe}(\mathrm{N} 2 \mathrm{Py} 2)$ complexes is through oxidative dimerization to form inactive oxo-bridged $\mathrm{Fe}_{2}(\mu$ $\mathrm{O})(\mathrm{N} 2 \mathrm{Py} 2)_{2}$ dimers. Detailed ESI-MS analysis has now shown a catalyst decomposition pathway of ligand oxidation

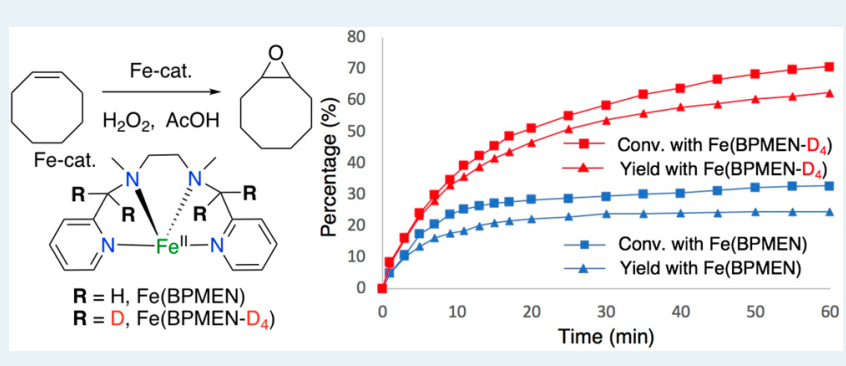
via $\mathrm{C}-\mathrm{H}$ oxidation on the 2-pyridinylmethylene sites, followed by dissociation of the oxidized ligand from the iron center. By deuterating the 2-pyridinylmethylene sites of a series of N2Py2 ligands with variations on both alkylamine and pyridine fragments, providing access to the corresponding $\mathrm{Fe}\left(\mathrm{N} 2 \mathrm{Py} 2-\mathrm{D}_{4}\right)$ complexes, longer catalysts lifetimes are achieved in catalytic oxidation reactions with all complexes. As a consequence, improved substrate conversions and product yields were consistently observed in both aliphatic $\mathrm{C}-\mathrm{H}$ oxidations and alkene epoxidations. Kinetic and catalytic studies revealed that deuteration does not change the intrinsic reactivity and product selectivity of $\mathrm{Fe}(\mathrm{N} 2 \mathrm{Py} 2)$ complexes. In addition, different $\mathrm{Fe}\left(\mathrm{N} 2 \mathrm{Py} 2-\mathrm{D}_{4}\right)$ complexes provide different improvements in catalytic performances and lifetimes, responding to the differences in ligand rigidity and robustness of the corresponding nondeuterated N2Py2 ligands. Accordingly, these improvements are more pronounced for ligands with a more flexible bisalkylamine backbone. These observations provide insights into the development of more robust ligands for homogeneous oxidation catalysis.

KEYWORDS: non-heme iron catalysts, catalyst decomposition, catalyst lifetime, ligand oxidation, N2Py2 ligands, oxidation reactions

\section{INTRODUCTION}

$\mathrm{C}-\mathrm{H}$ and $\mathrm{C}=\mathrm{C}$ bond oxidations constitute essential transformations in organic synthesis and in many biological and industrial processes. $^{1-6}$ These oxidations are performed routinely in a very selective manner in nature by heme and non-heme iron-containing enzymes via activation of $\mathrm{O}_{2}$. Taking inspiration from these iron enzymes, considerable efforts have been invested in the development of synthetic non-heme iron catalysts in the past two decades. ${ }^{7}$ These iron catalysts, especially those containing tetradentate nitrogen (N4, generally aminopyridine) ligands, are able to oxidize substrates with high regio- and stereoselectivities utilizing $\mathrm{H}_{2} \mathrm{O}_{2}$ as the oxidant. ${ }^{1,2,5}$ These selective oxidations are different from Fenton-like processes, which generally lead to unselective oxidations due to the involvement of highly reactive hydroxyl radicals. So far, iron complexes with a cis- $\alpha$ topology derived from aminopyridine ligands with a linear bisalkylamine-bis-pyridine (N2Py2) structure have been proven to be the most effective (Figure 1). ${ }^{1}$ On the basis of this ligand platform, modification of the N2Py2 ligand in the bisalkylamine backbone or the pyridine moieties allows for the improvement of the reactivity and for the fine-tuning of the

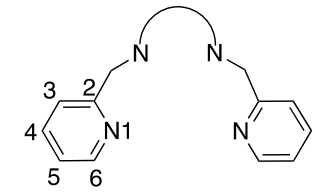

Figure 1. Generic structure of the linear N2Py2 ligand platform.

selectivity of the catalyst, providing powerful protocols for efficient $\mathrm{C}-\mathrm{H}$ and $\mathrm{C}=\mathrm{C}$ oxidations.

Nevertheless, the stability of such iron catalysts under the oxidizing conditions still remains a problem and attracts less attention, despite it being an important factor that affects catalyst efficiency. 8 ,9 The commonly accepted catalyst decomposition pathway of non-heme iron complexes is through oxidative dimerization to form inactive oxo-bridged $\mathrm{Fe}^{\mathrm{III}}{ }_{2}(\mu-\mathrm{O})(\mathrm{L})_{2}$ dimers $(\mathrm{L}=$ ligand $) .{ }^{10}$ These decomposition species have been proposed for several N2Py2-based iron complexes, such as $\left[\mathrm{Fe}(\mathrm{BPMEN})\left(\mathrm{CH}_{3} \mathrm{CN}\right)_{2}\right]\left(\mathrm{ClO}_{4}\right)_{2}{ }^{11}$ and

Received: November 6, 2018

Revised: January 11, 2019

Published: February 21, 2019 

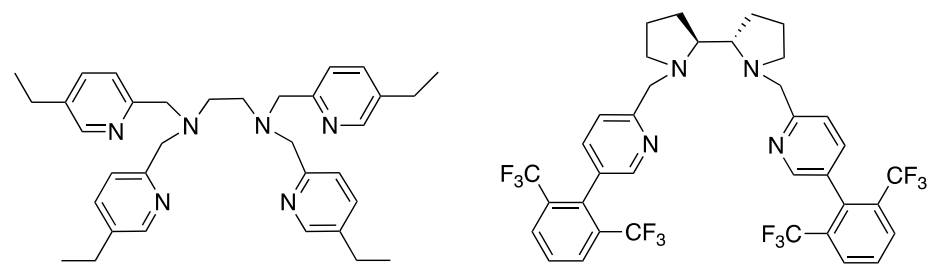

5-Et-TPEN

$S, S-\mathrm{CF}_{3}-\mathrm{BPBP}$

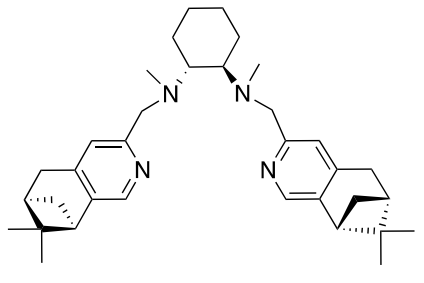

$R, R, R-\mathrm{mcpp}$

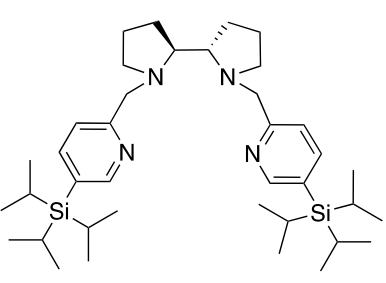

$S, S^{\mathrm{TIPS}} \mathrm{BPBP}$

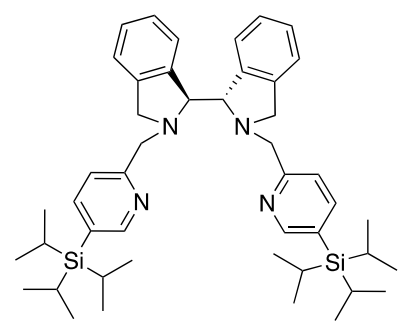

$S, S^{\text {TIPS}}$ BPBI

Figure 2. Some examples of N2Py2 ligands with increased steric bulk.

Scheme 1. Possible Ligand Oxidation Pathways for Amine-Based Non-Heme Iron Complexes ${ }^{a}$. Reproduced with Permission from Ref 9. Copyright 2014 Royal Society of Chemistry

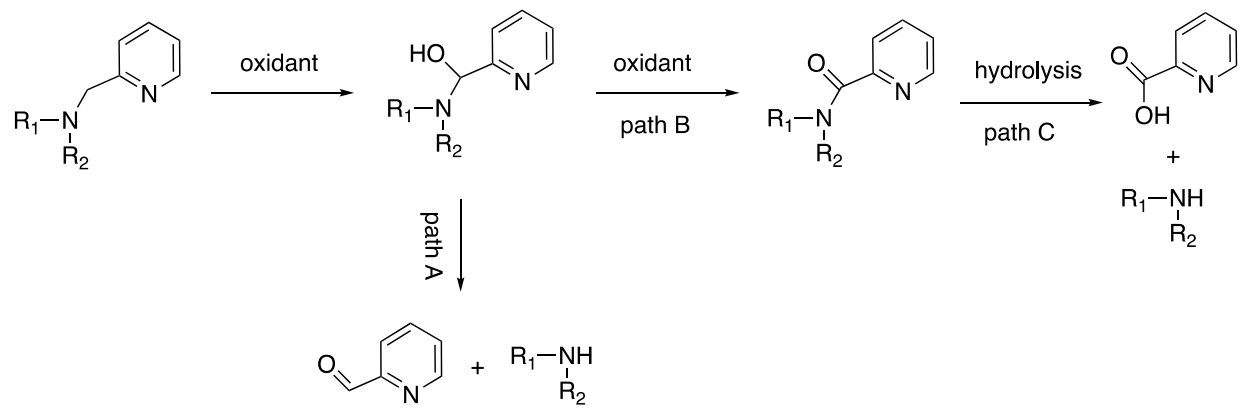

${ }^{a_{\text {The }}}$ metal center is omitted for clarity.

BPBP-based iron complexes, ${ }^{12-15}$ as well as for other $\mathrm{N} 4$ complexes like TPA-based iron complexes ${ }^{10}\left(\mathrm{BPMEN}=N, N^{\prime}\right.$ dimethyl- $N, N^{\prime}$-bis (2-picolyl)ethylenediamine, BPBP $=N, N^{\prime}$ bis (2-picolyl)-2,2'-bispyrrolidine, $\mathrm{TPA}=\operatorname{tris}(2$ pyridylmethyl)amine).

To suppress this catalyst decomposition pathway, a slow $\mathrm{H}_{2} \mathrm{O}_{2}$ addition protocol $1^{14,16-21}$ or an iterative addition protocol of a solution of catalyst, $\mathrm{H}_{2} \mathrm{O}_{2}$, and acetic acid ${ }^{22-27}$ have generally been adopted in reaction procedures. Modifications of the ligand by increasing the bulk of the pyridine fragments have also been reported to suppress the bimolecular self-decomposition pathway. Substituents at the 5positions, as in 5-Et-TPEN developed by Banse et al. ${ }^{28}$ or $\mathrm{CF}_{3}-\mathrm{BPBP}$ developed by White et al. ${ }^{24,29}$ (Figure 2), can shield the approach of another catalyst molecule toward the iron center, which in turn limits bimolecular self-decomposition (TPEN $=N, N, N^{\prime}, N^{\prime}$-tetrakis (2-pyridylmethyl)ethane1,2-diamine). In 2009, Costas et al. reported on the mcpp ligand in which bulky pinene moieties are placed at the 4- and 5 -positions of the pyridine rings $\left(\mathrm{mcpp}=N, N^{\prime}\right.$-dimethyl- $N, N^{\prime}$ bis $\{[(R)-4,5$-pinenepyridin-2-yl $]$-methyl $\}$-cyclohexane-1,2-diamine, Figure 2), resulting in reduced bimolecular selfdeactivation. ${ }^{12}$ The incorporation of bulky tris-(isopropyl)silyl (TIPS) groups at the 5-positions of pyridines in [Fe(OTf $\left.)_{2}\left(S, S-{ }^{\text {TIPS }} \mathrm{BPBP}\right)\right]$ has been shown to translate into improved substrate conversions (Figure 2$){ }^{20}$ which is likely because of suppression of the formation of $\mathrm{Fe}^{\mathrm{III}}{ }_{2}(\mu-\mathrm{O})(\mathrm{L})_{2}$ dimers. Similar observations were described for the catalytic performance of the iron complex derived from ${ }^{\mathrm{TIPS}} \mathrm{BPBI}$ in our previous study $\left(\mathrm{BPBI}=N, N^{\prime}\right.$-bis $(2$-picolyl $)-2,2^{\prime}$-bis-isoindoline). ${ }^{30}$

Another possible cause for catalyst decomposition is oxidative ligand degradation. For example, ligands bearing phenyl moieties are susceptible to aryl $\mathrm{C}-\mathrm{H}$ bond oxidation in the case that hydroxyl radicals are formed during catalysis. ${ }^{31-33}$ More importantly, the 2-pyridinylmethylene sites adjacent to an amine are vulnerable to oxidative degradation. For instance, this 2-pyridinylmethylene site can undergo hydroxylation to form a hemiaminal compound when exposed to the oxidant. ${ }^{34}$ One possible fate of this compound is $\mathrm{C}-\mathrm{N}$ bond cleavage to form an aldehyde ${ }^{28,35-40}$ and a secondary amine (Scheme 1, path A). Alternatively, the hemiaminal can be overoxidized into an amide intermediate (path B), ${ }^{34}$ which can potentially be hydrolyzed into a picolinic acid (path $\mathrm{C}$ ), as reported by Browne $^{40}$ and others. ${ }^{28,41,42}$ Efforts have been taken in order to prevent deleterious oxidations on the 2-pyridinylmethylene sites in N2Py2 ligands. For example, Britovsek et al. proposed to introduce a methyl group or a carbonyl linkage at the 2pyridinylmethylene positions in the BPMEN ligand. ${ }^{9}$ However, these ligand modifications led to inferior catalytic efficiencies of the corresponding iron complexes in $\mathrm{C}-\mathrm{H}$ bond oxidation, which was attributed to a change in ligand flexibility in the case of $-\mathrm{CH}_{3}$ introduction leading to less-active coordination 
modes (cis- $\beta$ and trans) or to the formation of inactive dinuclear complexes in the case of carbonyl introduction. ${ }^{9}$

Other investigations on the stability of non-heme iron oxidation catalysts have either focused on recovering the ligands or on ESI-MS (electrospray ionization mass spectrometry) analyses after catalysis. ${ }^{12,14,15}$ In a study by White and coworkers, $95 \%$ of nonoxidized BPBP ligand was recovered from a catalytic $\mathrm{C}-\mathrm{H}$ oxidation experiment where $[\mathrm{Fe}(\mathrm{BPBP})$ $\left.\left(\mathrm{CH}_{3} \mathrm{CN}\right)_{2}\right]\left(\mathrm{SbF}_{6}\right)_{2}$ was employed. ${ }^{14}$ In contrast, the oxidized ligand was identified as a major species in ESI-MS traces of oxidation reactions using the catalytically inactive $[\mathrm{Fe}$ $(\mathrm{OTf})_{2}(R, S$-BPBP $\left.)\right]$ complex, which features a cis- $\beta$ topological configuration. ${ }^{15}$ All reported catalyst decomposition studies were performed after the catalyst had been used in catalytic oxidations of organic substrates. Since catalytic conditions are often optimized to maximize product formation, these studies make use of rather different reaction conditions.

This paper describes the development of non-heme iron catalysts derived from $\mathrm{N} 2 \mathrm{Py} 2-\mathrm{D}_{4}$ ligands in which the 2pyridinylmethylene positions in the ligand framework have been per-deuterated (see Scheme 2). The development of

Scheme 2. Modification of N2Py2 Ligands through the Introduction of D Atoms on the 2-Pyridinylmethylene Positions

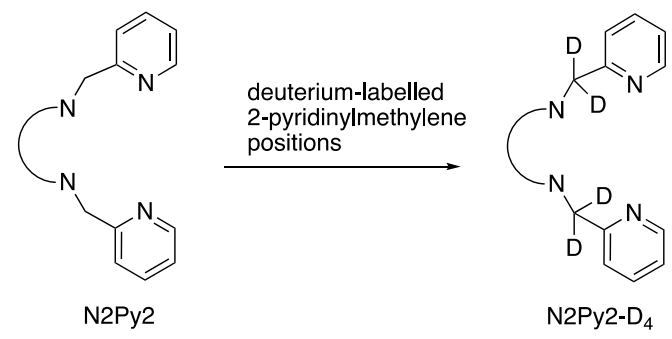

these ligands was inspired by the observation of significant ligand oxidation upon exposure of the parent, nondeuterated complexes to $\mathrm{H}_{2} \mathrm{O}_{2}$ in the absence of an organic substrate. This minor ligand alteration minimizes changes in the flexibility, and the steric and electronic properties of the ligands. The corresponding deuterated iron complexes were found to outperform the nondeuterated complexes in terms of substrate conversion and product yield in all cases studied.

\section{RESULTS AND DISCUSSION}

Catalyst Decomposition. The study was initiated by a simplified and dedicated decomposition experiment of $[\mathrm{Fe}-$ $(\mathrm{OTf})_{2}(S, S$-BPBP $\left.)\right]$ under typical catalytic conditions but in the absence of an organic substrate, by mixing the complex ( 1 equiv) with $\mathrm{H}_{2} \mathrm{O}_{2}$ (150 equiv) and $\mathrm{AcOH}$ (50 equiv) at $0{ }^{\circ} \mathrm{C}$ for $10 \mathrm{~min}$. ESI-MS analysis of the resulting mixture revealed a predominant peak at $m / z=337.1954$ (Figure 3a), with an isotopic pattern which is in agreement with an oxidized ligand carbonyl compound $(\mathrm{BPBP})=\mathrm{O}($ calcd $\mathrm{m} / \mathrm{z}$ for $[(\mathrm{BPBP})=\mathrm{O}$ $+\mathrm{H}]^{+}:$337.2029, Figure 3a, inset) resulting from aliphatic $\mathrm{C}-$ $\mathrm{H}$ oxidation of one of the methylene sites of the ligand. Of note is that no noticeable iron-containing species derived from the oxidized ligand product were found in the ESI-MS trace, suggesting that the oxidized ligand dissociates from the iron center. In addition, no dimeric oxo-complexes of the type $\mathrm{Fe}_{2}(\mu$-O $)(\mathrm{BPBP})_{2}$ were observed in this case.
These observations are significantly different from the notion that $\mathrm{Fe}(\mathrm{BPBP})$ decomposition occurs via dimerization reactions $^{12-15}$ and that no oxidized ligand was observed. ${ }^{14,15}$ In the catalyst decomposition study described by White et al., ${ }^{14}$ 95\% of the intact BPBP ligand was recovered. However, this analysis was conducted after a catalytic reaction in the presence of an alkane substrate and under distinctively different reaction conditions (substrate: cat: $\mathrm{H}_{2} \mathrm{O}_{2}: \mathrm{AcOH}=100: 15: 360: 0$ ).

The observed ligand oxidation is likely to happen at one of the 2-pyridinylmethylene positions of the ligand (vide supra), since these represent the weakest of all $\mathrm{C}-\mathrm{H}$ sites in the BPBP ligand (Figure $3 \mathrm{~b}$ ). Based on this observation and assumption, and according to the general concept of kinetic isotope effects, a stabilization of the 2-pyridinylmethylene positions in N2Py2 ligands in general would be achieved by replacing the 2pyridinylmethylene $\mathrm{H}$ atoms by $\mathrm{D}$ atoms. This would in turn make the corresponding $\mathrm{Fe}$ complexes more stable under the oxidizing conditions, leading to longer catalyst lifetimes and improved catalytic performances.

Synthesis of N2Py2-D $\mathrm{D}_{4}$ Ligands and Iron Complexes. A series of deuterium-labeled $\mathrm{N} 2 \mathrm{Py} 2-\mathrm{D}_{4}$ ligands have been synthesized following the synthesis scheme developed for the nondeuterated ligands (Figure 4). Key to the synthesis is the reduction of alkyl picolinate analogues by $\mathrm{NaBD}_{4}{ }^{43}$ followed by chlorination of the resulting hydroxymethylpyridine- $\mathrm{D}_{2}$ derivatives, ${ }^{44}$ to provide chloromethylpyridine- $\mathrm{D}_{2}$ compounds. These were readily converted into N2Py2- $\mathrm{D}_{4}$ ligands through alkylation of the appropriate alkylamine backbones. The first three ligands are derived from the well-known N2Py2 ligands BPBP, ${ }^{22}$ BPMCN ( $N, N^{\prime}$-dimethyl- $N, N^{\prime}$-bis(2-picolyl)-cyclohexane-trans-1,2-diamine), ${ }^{45}$ and $\mathrm{BPMEN},{ }^{46}$ which have different alkylamine backbones. Variation of the pyridine moieties has also been considered, that is, using isoquinoline rings as heteroaromatic fragments instead of pyridines in the BQMEN ligand (BQMEN = N,N'-dimethyl- $N, N^{\prime}$-bis (3isoquinolyl)ethylenediamine). By doing so, the applicability of this catalyst design strategy can be properly evaluated on the basis of variations in both the alkylamine and the pyridine fragments in the N2Py2 ligand platform. Ligands with incompletely deuterated 2-pyridinylmethylene sites (mainly N2Py2- $\mathrm{D}_{3}$ ) have been found to be present in minor amounts in all N2Py2-D $\mathrm{D}_{4}$ ligands reported here, as confirmed by ${ }^{1} \mathrm{H}$ NMR and ESI-MS (see Supporting Information).

Using $\mathrm{Fe}(\mathrm{OTf})_{2} \cdot 2 \mathrm{CH}_{3} \mathrm{CN}$ as iron precursor, iron complexes $\mathbf{1}-\mathrm{D}_{4}, \mathbf{3}-\mathrm{D}_{4}$, and $\mathbf{4}-\mathrm{D}_{4}$ were synthesized through complexation with the corresponding ligands in THF (Figure 4). The synthesis of $\mathbf{2}-\mathrm{D}_{4}{ }^{47}$ was accomplished using $\mathrm{FeCl}_{2}$ as iron precursor, followed by the treatment with $\mathrm{Ag}(\mathrm{OTf}) .{ }^{48}$ From ESI-MS, minor amounts of the $\left[\mathrm{Fe}(\mathrm{OTf})_{2}\left(\mathrm{~N} 2 \mathrm{Py} 2-\mathrm{D}_{3}\right)\right]$ complexes were noted in each $\mathrm{N} 2 \mathrm{Py} 2-\mathrm{D}_{4}$ complex as a consequence of the $\mathrm{N} 2 \mathrm{Py} 2-\mathrm{D}_{3}$ impurity (see Supporting Information). For comparison purposes, the parent nondeuterated iron complexes 1-4 were also synthesized.

Confirmation of the Oxidized Site and Proposed Ligand Oxidation Pathway. With the $\mathrm{Fe}\left(\mathrm{N} 2 \mathrm{Py} 2-\mathrm{D}_{4}\right)$ complexes in hand, the postulated site of ligand oxidation could be confirmed. To do so, the oxidation of $1-\mathbf{D}_{4}$ was performed using the same reaction conditions as in the oxidation of 1 (vide supra). ESI-MS analysis showed the presence of the oxidized ligand product at $\mathrm{m} / z=339.2085$ (Figure 5), which corresponds to a mass difference of 12 from the $\mathrm{BPBP}_{-} \mathrm{D}_{4}$ ligand (calcd $m / z=327.2481$ ). This clearly indicates that $\mathrm{C}-\mathrm{H}$ oxidation takes place on one of the 


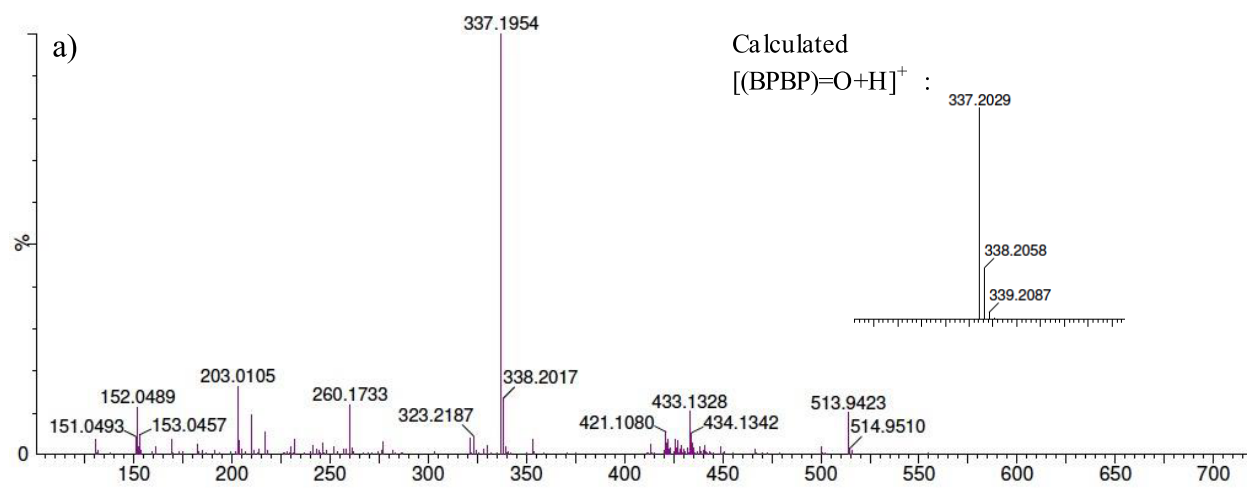

b)

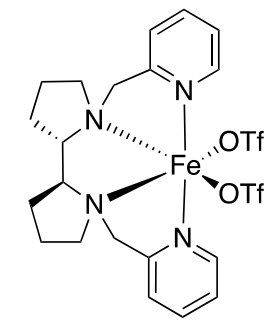

$\left[\mathrm{Fe}(\mathrm{OTf})_{2}(S, S\right.$-BPBP $\left.)\right]$

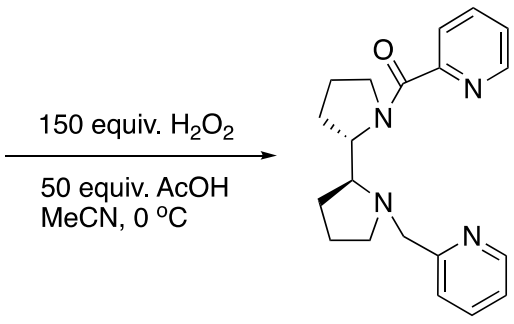

$(\mathrm{BPBP})=\mathrm{O}$

Figure 3. (a) ESI-MS trace of the mixture from a reaction of $\left[\mathrm{Fe}(\mathrm{OTf})_{2}(S, S-\mathrm{BPBP})\right](2 \mathrm{mM})$ with $\mathrm{H}_{2} \mathrm{O}_{2}$ (150 equiv) and AcOH (50 equiv) in $\mathrm{MeCN}$, stirred at $0{ }^{\circ} \mathrm{C}$ for $10 \mathrm{~min}$. ESI-MS was directly measured for the reaction mixture without any workup. The peak at $\mathrm{m} / z=337.1946$ corresponds to the decomposition compound $(\mathrm{BPBP})=\mathrm{O}$, calcd $m / z$ for $\mathrm{C}_{20} \mathrm{H}_{27} \mathrm{~N}_{4} \mathrm{O}\left([\mathrm{M}+\mathrm{H}]^{+}\right): 337.2029$ (inset). A minor peak corresponding to free BPBP ligand was also present, with a $\mathrm{m} / \mathrm{z}$ value of 323.2189 (calcd $\mathrm{m} / \mathrm{z}$ for $[\mathrm{BPBP}+\mathrm{H}]^{+}: 323.2230$ ). (b) Proposed decomposition pathway of $\left[\mathrm{Fe}(\mathrm{OTf})_{2}(S, S-\mathrm{BPBP})\right]$ into amide compound $(\mathrm{BPBP})=\mathrm{O}$ with one 2-pyridinylmethylene position oxidized.

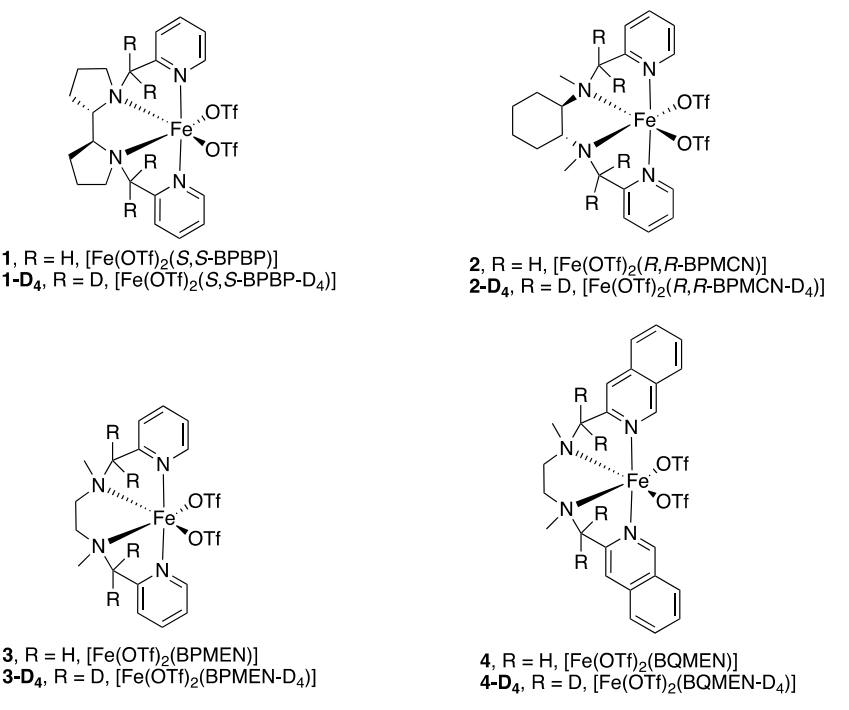

Figure 4. $\left[\mathrm{Fe}(\mathrm{OTf})_{2}(\mathrm{~N} 2 \mathrm{Py} 2)\right]$ and $\left[\mathrm{Fe}(\mathrm{OTf})_{2}\left(\mathrm{~N} 2 \mathrm{Py} 2-\mathrm{D}_{4}\right)\right]$ complexes studied in this paper.

deuterated 2-pyridinylmethylene positions to form (BPBP$\left.\mathrm{D}_{2}\right)=\mathrm{O}\left(\right.$ calcd $m / z$ for $[\mathrm{M}+\mathrm{H}]^{+}: 339.2185$, Figure 5 , inset $)$. The small peak at $m / z=338$ is due to oxidation of the $1-\mathbf{D}_{3}$ ligand, which is present in small amounts in $1-\mathbf{D}_{4}$. More importantly, no noticeable species were observed that represent ligand oxidation on nondeuterated methylene sites (calcd $m / z=341.2274$ ), meaning that ligand oxidation predominantly takes place on the 2-pyridinylmethylene positions. Notably, in this case, binuclear oxo-bridged dimers resulting from bimolecular self-decomposition pathways were observed in high intensities. The two peaks at $\mathrm{m} / z=279.7833$ and 494.1451 are assigned to the binuclear species $\left[\mathrm{Fe}_{2}(\mu\right.$ O) $\left.\left(\mathrm{BPBP}_{-} \mathrm{D}_{4}\right)_{2}(\mathrm{OAc})\right]^{3+}(\mathrm{calcd} m / \mathrm{z}=279.7861)$ and $\left[\mathrm{Fe}_{2}(\mu\right.$ O) $(\text { BPBP-D })_{2}($ OAc $)($ OTf $\left.)\right]^{2+}($ calcd $m / z=494.1554)$, respectively. This clearly indicates that $1-D_{4}$ more preferentially undergoes the aforementioned bimolecular self-decomposition pathway, which is assumed to be the consequence of less favorable $\mathrm{CD}_{2}$ oxidation. The peak at $\mathrm{m} / z=493.6447$ is again due to the presence of incompletely deuterated ligand. Similar to the ligand oxidation experiment of $\mathbf{1}$, no noticeable iron-containing species containing the oxidized ligand were observed, meaning that the oxidized ligand dissociates from iron.

From the oxidation experiments using $\mathbf{1}$ and $\mathbf{1}-\mathbf{D}_{\mathbf{4}}$, it was concluded that one of the oxidative decomposition compounds of $\mathbf{1}$ and $\mathbf{1 - \mathbf { D } _ { 4 }}$ in the presence of $\mathrm{H}_{2} \mathrm{O}_{2}$ and $\mathrm{AcOH}$ is amide $(\mathrm{BPBP})=\mathrm{O}$ or $\left(\mathrm{BPBP}-\mathrm{D}_{2}\right)=\mathrm{O}$, respectively, formed through $\mathrm{C}-\mathrm{H}$ oxidation of one of the 2-pyridinylmethylene positions in the ligand. It is evident that this oxidation process includes at least two steps: ligand oxidation and dissociation from iron. Under catalytic conditions these events would lead to catalyst decomposition/deactivation and deterioration of catalytic activity over time.

In order to obtain insight into the ligand oxidation process, the oxidation of the free BPBP ligand was carried out in the presence of an equal amount of $\mathbf{1}-\mathrm{D}_{4}, 150$ equiv of $\mathrm{H}_{2} \mathrm{O}_{2}$, and 50 equiv of $\mathrm{AcOH}$ (Figure 6a). After the mixture was stirred at $0{ }^{\circ} \mathrm{C}$ for $10 \mathrm{~min}$, a sample of the reaction mixture was subjected to ESI-MS analysis, showing unreacted ligand BPBP $(m / z=323.2210)$ as the predominant species and no obvious formation of $(\mathrm{BPBP})=\mathrm{O}$ (Figure $6 \mathrm{~b}, \mathrm{I})$. In addition, in a separate reaction of BPBP (1 equiv), 1 ( 2 mol \%), $\mathrm{H}_{2} \mathrm{O}_{2}(1.2$ equiv), and $\mathrm{AcOH}$ (50 mol \%) for $30 \mathrm{~min}$, only intact $\mathrm{BPBP}$ was observed both in ${ }^{1} \mathrm{H}$ NMR and ESI-MS. Combining these 


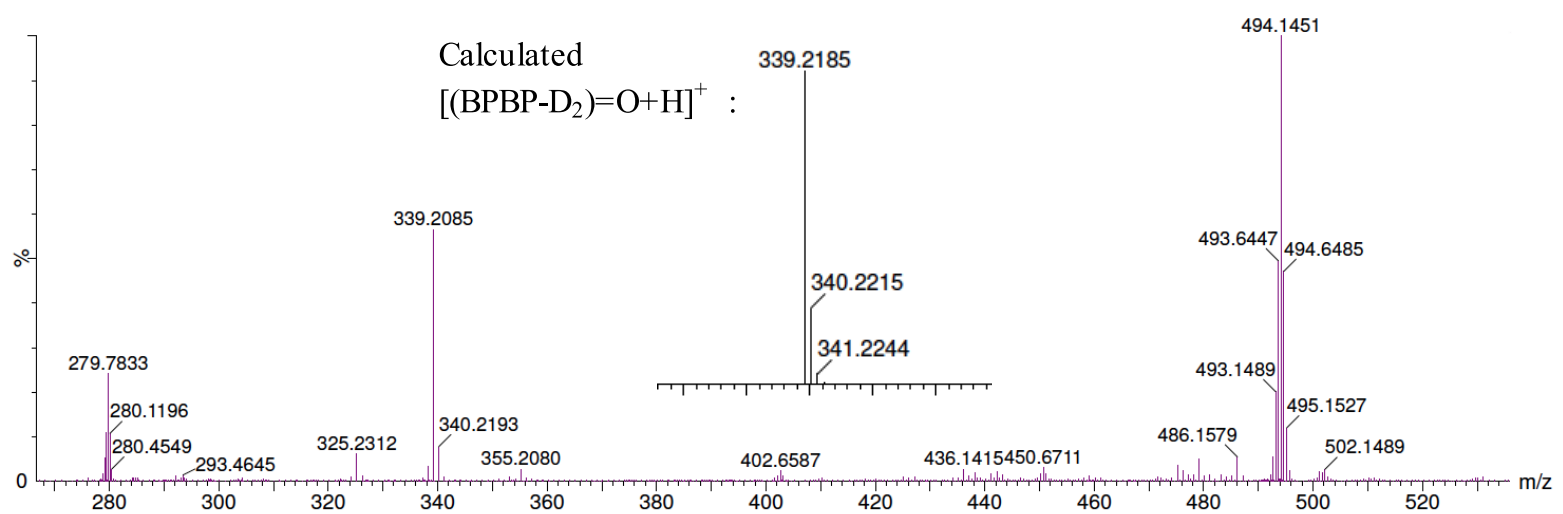

Figure 5. ESI-MS of the mixture from the reaction of $1-\mathrm{D}_{4}(2 \mathrm{mM})$ with $\mathrm{H}_{2} \mathrm{O}_{2}$ (150 equiv) and $\mathrm{AcOH}\left(50\right.$ equiv) in $\mathrm{MeCN}$, stirred at $0{ }^{\circ} \mathrm{C}$ for 10 min. ESI-MS was directly measured for the reaction mixture without any workup. The peak at $\mathrm{m} / z=339.2085$ corresponds to the decomposition amide compound $\left(B P B P-\mathrm{D}_{2}\right)=\mathrm{O}$ (inset: calcd $m / z$ for $\mathrm{C}_{28} \mathrm{H}_{27} \mathrm{~N}_{4}\left([\mathrm{M}+\mathrm{H}]^{+}\right)$: 339.2185).

observations, it is clear that it is difficult for the free BPBP ligand to undergo $\mathrm{C}-\mathrm{H}$ oxidation by the $\mathrm{Fe}\left(\mathrm{BPBP}_{\mathrm{D}} \mathrm{D}_{4}\right)$ / $\mathrm{H}_{2} \mathrm{O}_{2} / \mathrm{AcOH}$ catalytic system. In comparison, the deactivation of 1 produces $(\mathrm{BPBP})=\mathrm{O}$ as the major decomposition compound within $10 \mathrm{~min}$ (Figure 3a), which excludes a scenario in which the BPBP ligand dissociates from iron first, followed by $\mathrm{C}-\mathrm{H}$ oxidation of BPBP in the presence of the $\mathrm{Fe}(\mathrm{BPBP}) / \mathrm{H}_{2} \mathrm{O}_{2} / \mathrm{AcOH}$ catalytic system.

As expected, the decomposition compound $\left(\mathrm{BPBP}_{-} \mathrm{D}_{2}\right)=\mathrm{O}$ $(m / z=339.2197$, Figure $6 \mathrm{~b}, \mathrm{I})$ derived from the oxidation of 1-D $\mathrm{D}_{4}$ was observed next to intact BPBP ligand in the experiment in which BPBP and $\mathbf{1}-\mathbf{D}_{\mathbf{4}}$ were combined (Figure 6a). A similar ESI-MS trace was obtained by allowing this reaction to continue for another $30 \mathrm{~min}$, with $\mathrm{BPBP}$ as major species and $\left(B P B P-D_{2}\right)=\mathrm{O}$ as minor species (Figure $6 \mathrm{~b}, \mathrm{II}$ ). After another hour at room temperature (RT), the $\mathrm{C}-\mathrm{H}$ oxidation product of BPBP started to appear at $\mathrm{m} / z=$ 337.1917 (assigned to $(\mathrm{BPBP})=\mathrm{O})$, along with small amounts of secondary hydroxylation products derived from the initial

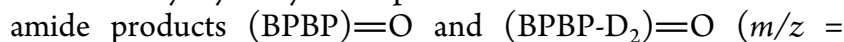
353.1915 for $\mathrm{HO}-(\mathrm{BPBP})=\mathrm{O}$ and $m / z=355.2047$ for $\mathrm{HO}-$ $\left(\mathrm{BPBP}-\mathrm{D}_{2}\right)=\mathrm{O}$ or $\mathrm{DO}-(\mathrm{BPBP}-\mathrm{D})=\mathrm{O}$; Figure $6 \mathrm{~b}$, III $)$. Nevertheless, unreacted BPBP still represented the predominant species in the reaction mixture after a total of $100 \mathrm{~min}$ of reaction time (Figure 6b, III). Subsequently, the signal at $\mathrm{m} / \mathrm{z}$ $=323(\mathrm{BPBP})$ disappeared after stirring overnight $(\mathrm{ON})$ at $\mathrm{RT}$, and the concentration of the oxidized product (BPBP)= $\mathrm{O}$ was found to be increased accordingly (Figure $6 \mathrm{~b}, \mathrm{IV}$ ). This means that the longer reaction time eventually leads to full conversion of BPBP into aliphatic oxidation products. At the same point in time, the amide product derived from the BPBP$\mathrm{D}_{4}$ ligand was also found at considerable concentration after the overnight reaction. As shown in Figure $6 \mathrm{~b}$, free BPBP is relatively stable in the presence of the $\mathrm{Fe} / \mathrm{H}_{2} \mathrm{O}_{2} / \mathrm{AcOH}$ catalytic system at the early stage of the reaction. However, free BPBP was also found to be oxidized into oxidized compounds at the late stage of the reaction. It is speculated that as the dissociation of the oxidized $B P B P-D_{4}$ ligand from iron proceeds, free BPBP can subsequently bind to the released iron ions to form the (oxidatively) active species, which in turn can get involved in ligand oxidation leading to the oxidation of BPBP.

On the basis of these observations, BPBP ligand oxidation leading to ligand dissociation is proposed to take place in an intramolecular fashion (i.e. when the ligand is bound to an iron center, and that intermolecular ligand oxidation does not take place). This notion strengthens the hypothesis that enhancing the oxidative robustness of the 2-pyridinylmethylene positions of the BPBP ligand would lead to an increased catalyst lifetime.

Catalytic Performances. To investigate the catalytic performances of the $\left[\mathrm{Fe}(\mathrm{OTf})_{2}\left(\mathrm{~N} 2 \mathrm{Py} 2-\mathrm{D}_{4}\right)\right]$ complexes, several alkenes were chosen as benchmark substrates to examine catalytic epoxidation. For comparison purposes, for each catalyst, a parallel experiment with the corresponding $\left[\mathrm{Fe}(\mathrm{OTf})_{2}(\mathrm{~N} 2 \mathrm{Py} 2)\right]$ complex was also carried out. The catalytic results are displayed in Table 1. cis-Cyclooctene (5) was epoxidized in the presence of $\mathbf{1}(0.25 \mathrm{~mol} \%), \mathrm{H}_{2} \mathrm{O}_{2}(100$ $\mathrm{mol} \%)$, and $\mathrm{AcOH}(1.5 \mathrm{~mol} \%),{ }^{15}$ giving rise to $84 \%$ conversion and $75 \%$ yield of epoxide 6 . Under the same reaction conditions, the reaction with $1-\mathrm{D}_{4}$ gave a slightly higher conversion and yield of $89 \%$ and $80 \%$, respectively. Despite these differences, these two reactions showed identical epoxide selectivities ( $89 \%$ for $\mathbf{1}$ and $90 \%$ for $\left.\mathbf{1}-\mathbf{D}_{4}\right)$. Interestingly, both conversion and yield increased with $14 \%$ when changing catalyst from 2 (73\% conversion and 64\% yield) to $2-\mathbf{D}_{4}$ (87\% conversion and $78 \%$ yield). More significant differences were found in the cases of 3 and $3-\mathbf{D}_{4}$. Cyclooctene epoxidation with $3-\mathbf{D}_{4}$ provides a more than 2 fold higher conversion and yield than the reaction carried out with 3 (70\% vs $34 \%$ conversion, and $57 \%$ vs $27 \%$ yield, respectively). A remarkable improvement in catalytic performance was also found in the reaction catalyzed by $4-\mathrm{D}_{4}$, with $43 \%$ conversion and $35 \%$ yield. In contrast, only $26 \%$ conversion and $20 \%$ yield were found in the case of 4 using the current conditions.

Two more alkene substrates, cis-4-octene and cyclohexenone, were tested next. Similar trends were found in all the reactions with the current set of catalysts; that is, the reactions with $\mathrm{Fe}\left(\mathrm{N} 2 \mathrm{Py} 2-\mathrm{D}_{4}\right)$ catalysts showed increased conversions and yields with respect to the reactions with $\mathrm{Fe}(\mathrm{N} 2 \mathrm{Py} 2)$ catalysts. In the epoxidation of cis-4-octene (7), the deuterated catalysts $1-D_{4}-4-D_{4}$ performed the reaction with a $16 \%, 8 \%, 18 \%$, and $8 \%$ increase in conversion with respect to nondeuterated catalysts 1-4, respectively. Similarly, in the case of cyclohexenone (9) epoxidation, 9\%, $8 \%, 18 \%$, and $5 \%$ more substrate was converted in the reactions with 1$\mathrm{D}_{4}-4-\mathrm{D}_{4}$, compared to the reactions with $1-4$, respectively. On the other hand, no major differences were observed in terms of epoxide selectivity between the parent and deuterated catalysts in these reactions, albeit that in most cases 
a)

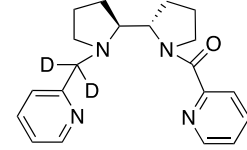

$\left(\mathrm{BPBP}-\mathrm{D}_{2}\right)=\mathrm{O}$

$\mathrm{m} / \mathrm{z}=339.2148\left([\mathrm{M}+\mathrm{H}]^{+}\right)$

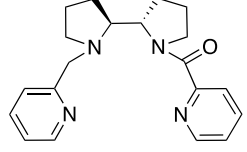

$(\mathrm{BPBP})=\mathrm{O}$

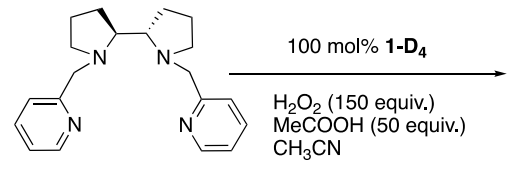

$S, S$-BPBP $m / z=323.2230\left([\mathrm{M}+\mathrm{H}]^{+}\right)$

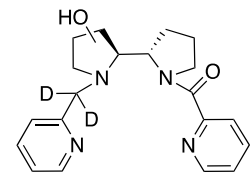

$\mathrm{HO}-\left(\mathrm{BPBP}-\mathrm{D}_{2}\right)=\mathrm{O}$

$\mathrm{m} / \mathrm{z}=355.2098\left([\mathrm{M}+\mathrm{H}]^{+}\right)$

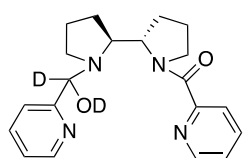

DO- (BPBP-D) $=0$ $\mathrm{m} / \mathrm{z}=355.2098\left([\mathrm{M}+\mathrm{H}]^{+}\right)$

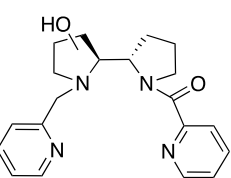

$\mathrm{HO}^{-}(\mathrm{BPBP})=\mathrm{O}$

$\mathrm{m} / \mathrm{z}=353.1972\left([\mathrm{M}+\mathrm{H}]^{+}\right)$

b)
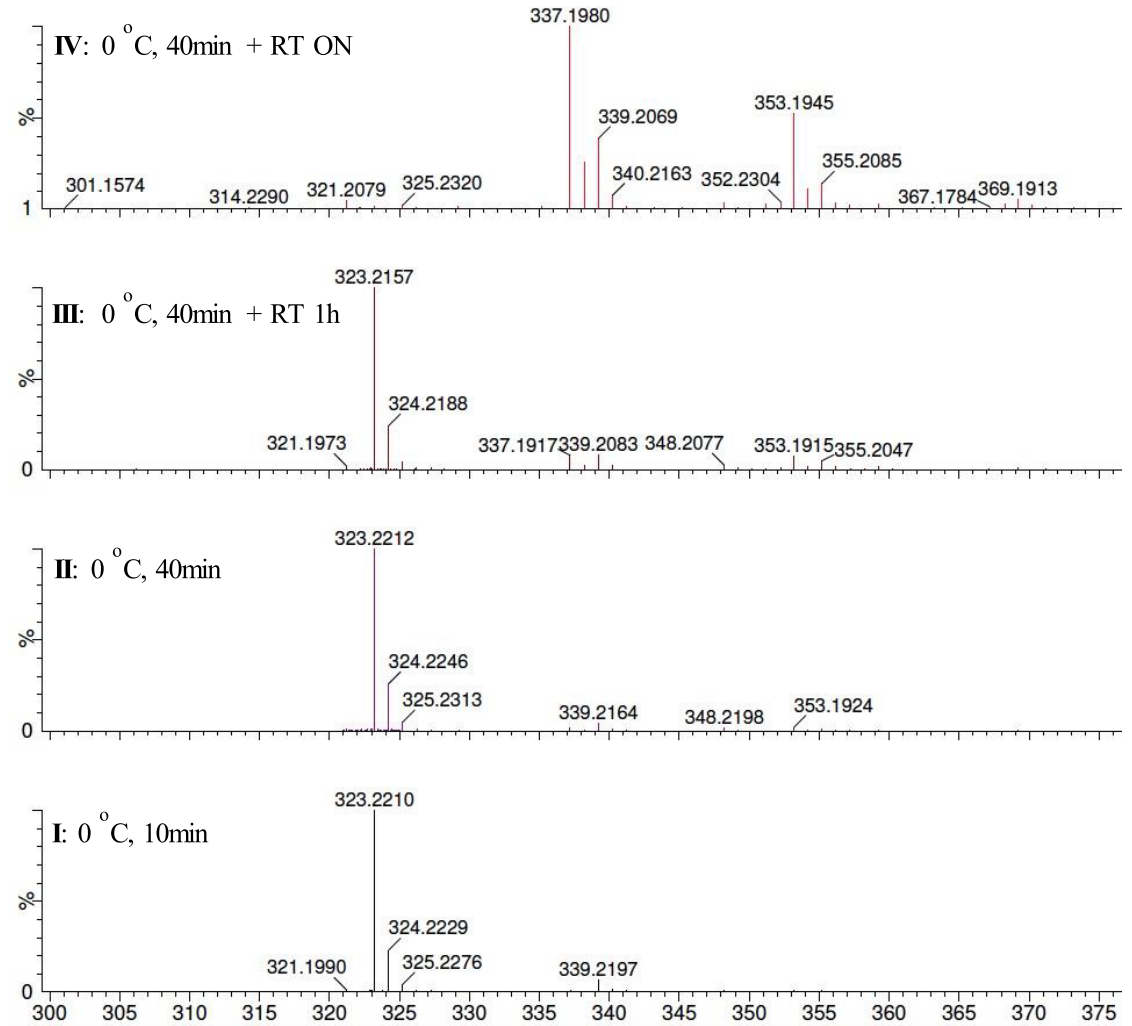

Figure 6. (a) Reaction of $S, S$-BPBP in the presence of $100 \mathrm{~mol} \% \mathbf{1}-\mathrm{D}_{4}, 150$ equiv of $\mathrm{H}_{2} \mathrm{O}_{2}$, and 50 equiv of AcOH. The oxidized ligand compounds from BPBP and BPBP-D $\mathrm{D}_{4}$ can be easily discriminated in ESI-MS due to deuterium labeling on the 2-pyridinylmethylene carbons. (b) ESI-MS of the reaction mixture of $S, S$-BPBP ( 1 equiv), $100 \mathrm{~mol} \% \mathbf{1}-\mathrm{D}_{4}, 150$ equiv of $\mathrm{H}_{2} \mathrm{O}_{2}$, and 50 equiv of AcOH over time. ESI-MS was directly measured for the reaction mixture without any workup. The aldehyde compounds derived from amide compounds $(B P B P)=O$ and $\left(B P B P-D_{2}\right)=$ $\mathrm{O}$ as shown in Scheme 1 were also observed in IV (not shown in the figure).

selectivities are slightly higher for the deuterated catalysts (Table 1).

Next to alkene epoxidation, the catalytic oxidation of aliphatic $\mathrm{C}-\mathrm{H}$ bonds by $\left[\mathrm{Fe}(\mathrm{OTf})_{2}\left(\mathrm{~N} 2 \mathrm{Py} 2-\mathrm{D}_{4}\right)\right]$ complexes was also examined (Table 2). Using $1.0 \mathrm{~mol} \%$ catalyst loading, cis-1,2-dimethylcyclohexane (11) was oxidized in the presence of $120 \mathrm{~mol} \%$ oxidant and $50 \mathrm{~mol} \% \mathrm{AcOH}^{30}$ generating $3^{\circ}$ oxidation product cis-12 as the major product, while trans-12 and $2^{\circ}$ oxidation products 13 and $\mathbf{1 4}$ were formed as minor products. When 1 was used as catalyst, $52 \%$ conversion, $30 \%$ total yield, and a 8.8 ratio of tertiary over secondary products $\left(3^{\circ} / 2^{\circ}\right)$ were obtained. The alcohol products showed a high retention of the substrate configuration, as an RC of $99 \%$ was obtained ( $\mathrm{RC}=$ retention of configuration $) . \mathbf{1}-\mathbf{D}_{4}$ provided an improvement in catalytic performance, with $62 \%$ coversion and
$38 \%$ total yield. Diastereopurity and selectivity toward the oxidation of $3^{\circ}$ over $2^{\circ}$ sites remained the same though $(\mathrm{RC}=$ $99 \%$ and $3^{\circ} / 2^{\circ}=8.8$, respectively). Complexes 2 and $2-D_{4}$ showed a similar catalytic performance with respect to each other, albeit with higher conversions and product yields, and a lower $3^{\circ} / 2^{\circ}$ product ratio compared to 1 and $1-D_{4}$. These results are in accordance with the previous observation by Costas et al., in which the BPMCN-based iron catalyst is more active and shows a higher preference toward $2^{\circ}$ oxidation than BPBP-based catalysts in $\mathrm{C}-\mathrm{H}$ oxidations. ${ }^{27}$ Similar to the reactions with $\mathbf{1}$ and $\mathbf{1}-\mathrm{D}_{\mathbf{4}}$, cis-12 was obtained nearly as a single diastereomer $(\mathrm{RC}=99 \%)$ using either $\mathbf{2}$ or $\mathbf{2}-\mathbf{D}_{\mathbf{4}}$. In contrast, significant differences in reactivity were noted between the reactions with 3 and $3-D_{4}$. The oxidation of 11 catalyzed by 3 gave rise to $41 \%$ conversion and $27 \%$ yield, 
Table 1. Catalytic Epoxidation of Alkenes by $\mathrm{Fe}(\mathrm{N} 2 \mathrm{Py} 2)$ vs $\mathrm{Fe}\left(\mathrm{N} 2 \mathrm{Py}_{2}-\mathrm{D}_{4}\right)$ Complexes $^{a}$

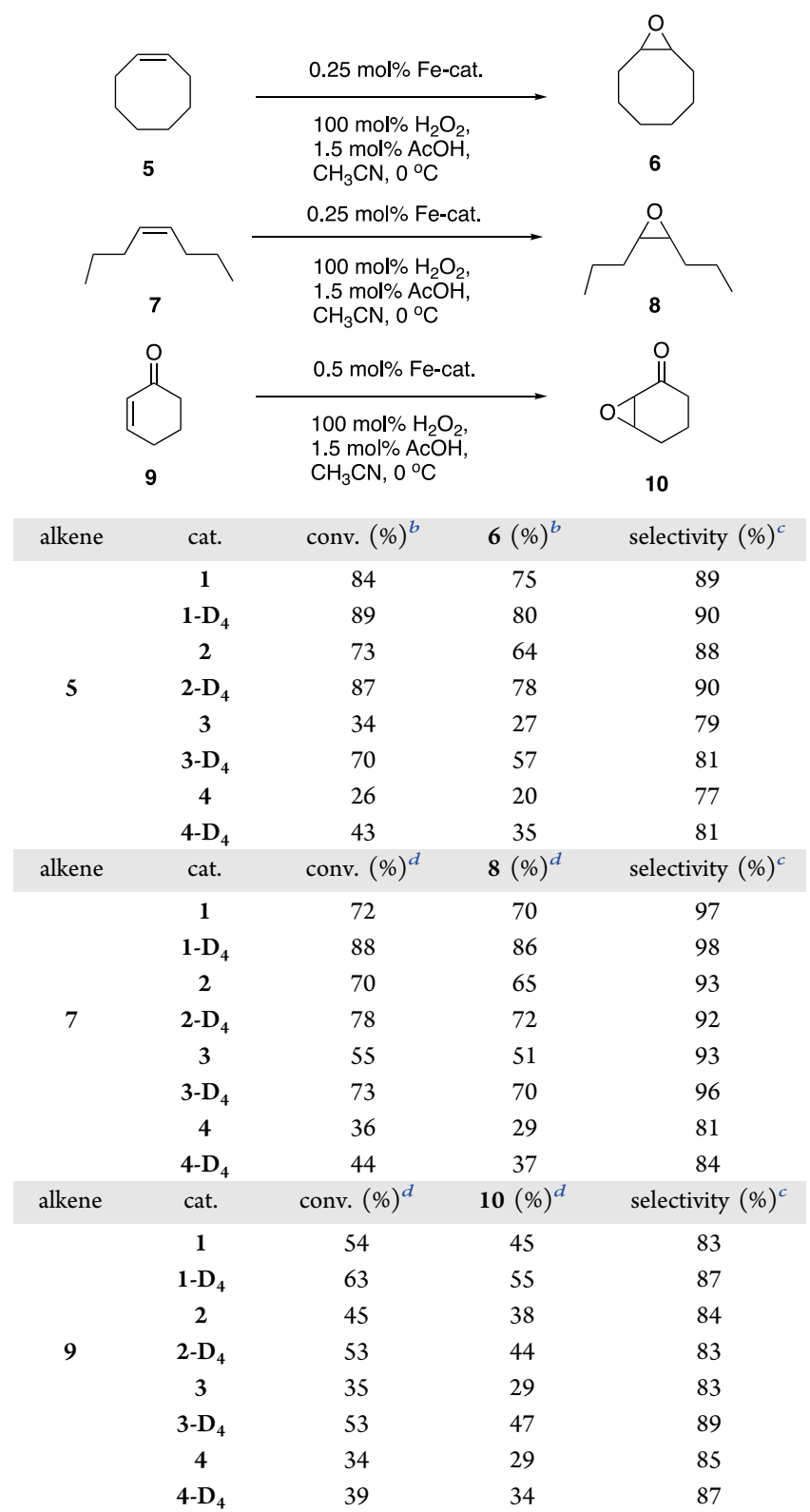

${ }^{a}$ Reaction conditions: Fe-cat.: $\mathrm{H}_{2} \mathrm{O}_{2}$ : substrate: $\mathrm{AcOH}=0.25$ (or 0.5 ): $100: 100: 1.5,0{ }^{\circ} \mathrm{C}$, oxidant added by syringe pump over $10 \mathrm{~min}$, and reaction mixture stirred for additional $30 \mathrm{~min}$. Reported analysis data represent the outcome of at least two independent catalysis experiments. ${ }^{b}$ Determined by GC analysis. ${ }^{c}$ Epoxide selectivity. ${ }^{d}$ Determined by NMR analysis.

while with $3-\mathbf{D}_{4}$ substrate conversion and yield increased to $56 \%$ and $39 \%$, respectively. Similarly, $4-\mathbf{D}_{4}$ provided a noticeable increase in conversion and yield compared to 4 , with $22 \%$ conversion and $19 \%$ yield in the case of 4 , and $31 \%$ conversion and $28 \%$ yield in the case of $4-\mathrm{D}_{4}$. Notably, similar $\mathrm{RC}$ values and $3^{\circ} / 2^{\circ}$ ratios were obsvered in these two sets of reactions.

In the oxidation of adamantane (15), noticeably different catalytic results were only found between the reactions with 1 and $1-\mathrm{D}_{4}$, with an improved conversion (from $73 \%$ to $82 \%$ ) and yield (from $42 \%$ to $50 \%$ ) for $\mathbf{1}-\mathbf{D}_{4}$. For the other three sets of reactions, slighly higher conversions and yields were found
Table 2. Catalytic C-H Oxidation of Alkanes by $\mathrm{Fe}(\mathrm{N} 2 \mathrm{Py} 2)$ vs $\mathrm{Fe}\left(\mathrm{N} 2 \mathrm{Py}_{2}-\mathrm{D}_{4}\right)$ Complexes $^{a}$
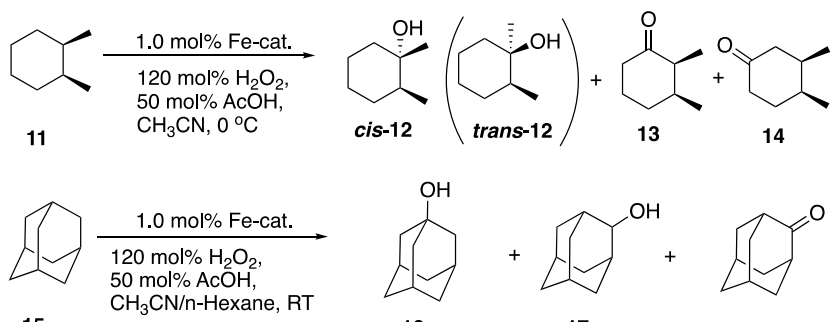

15

16

\begin{tabular}{|c|c|c|c|c|c|c|}
\hline alkane & cat. & conv. $(\%)^{b}$ & $\begin{array}{l}\text { cis-12, trans-12, } \\
13,14(\%)^{b}\end{array}$ & $\begin{array}{l}\text { total } \\
\text { yield } \\
(\%)^{b}\end{array}$ & $\begin{array}{l}\mathrm{RC} \\
(\%)^{c}\end{array}$ & $3^{\circ} / 2^{\circ \circ}$ \\
\hline \multirow{8}{*}{11} & 1 & 52 & $27,0.4,1.3,1.8$ & 30 & 99 & 8.8 \\
\hline & $1-\mathrm{D}_{4}$ & 62 & $34,0.5,1.8,2.1$ & 38 & 99 & 8.8 \\
\hline & 2 & 67 & $40,0.3,3.0,4.0$ & 47 & 99 & 5.7 \\
\hline & $2-\mathrm{D}_{4}$ & 70 & $42,0.3,3.3,4.3$ & 50 & 99 & 5.6 \\
\hline & 3 & 41 & $24,0.3,1.5,1.6$ & 27 & 99 & 7.8 \\
\hline & $3-\mathrm{D}_{4}$ & 56 & $34,0.4,2.2,2.5$ & 39 & 99 & 7.3 \\
\hline & 4 & 22 & $17,0.4,0.7,0.9$ & 19 & 98 & 10.8 \\
\hline & $4-\mathrm{D}_{4}$ & 31 & $25,0.5,1.1,1.5$ & 28 & 98 & 9.8 \\
\hline alkane & cat. & conv. $(\%)^{b}$ & $16,17,18(\%)^{b}$ & \multicolumn{2}{|c|}{ total yield $(\%)^{b}$} & $3^{\circ} / 2^{\circ \circ}$ \\
\hline \multirow{8}{*}{15} & 1 & 73 & $38,1.3,2.5$ & \multicolumn{2}{|c|}{42} & 30 \\
\hline & $1-\mathrm{D}_{4}$ & 82 & $45,1.6,2.9$ & \multicolumn{2}{|c|}{50} & 30 \\
\hline & 2 & 76 & $36,1.5,2.7$ & \multicolumn{2}{|c|}{40} & 26 \\
\hline & $2-\mathrm{D}_{4}$ & 79 & $38,1.6,2.9$ & \multicolumn{2}{|c|}{43} & 25 \\
\hline & 3 & 71 & $31,1.5,1.9$ & \multicolumn{2}{|c|}{34} & 27 \\
\hline & $3-\mathrm{D}_{4}$ & 72 & $33,1.6,2.2$ & \multicolumn{2}{|c|}{37} & 26 \\
\hline & 4 & 70 & $41,1.7,2.6$ & \multicolumn{2}{|c|}{45} & 29 \\
\hline & 4- $\mathrm{D}_{4}$ & 75 & $44,1.9,2.5$ & \multicolumn{2}{|c|}{48} & 30 \\
\hline
\end{tabular}

${ }^{a}$ Reaction conditions: Fe-cat.: $\mathrm{H}_{2} \mathrm{O}_{2}$ : substrate: $\mathrm{AcOH}=1$ : 120:100:50, $0{ }^{\circ} \mathrm{C}$ or RT, oxidant added by syringe pump over 10 min, and reaction mixture stirred for additional $30 \mathrm{~min}$. Reported analysis data represent the outcome of at least two independent catalysis experiments. ${ }^{b}$ Determined by GC analysis. ${ }^{c} \mathrm{RC}$ (retention of configuration $)=$ cis-12/(cis-12+trans-12) $* 100 \%$. ${ }^{d} 3^{\circ} / 2^{\circ}=($ cis$12+$ trans-12) $/(13+14) .{ }^{e} 3^{\circ} / 2^{\circ}=3 * 16 /(17+18)$.

in the reactions with the $\mathrm{Fe}\left(\mathrm{N} 2 \mathrm{Py} 2-\mathrm{D}_{4}\right)$ catalyst than the ones with the $\mathrm{Fe}(\mathrm{N} 2 \mathrm{Py} 2)$ catalyst (Table 2$)$. In none of these reaction sets was a change in the $3 \% / 2^{\circ}$ product ratio observed.

Kinetic Studies. In all the oxidative reactions tested, both alkene epoxidations and aliphatic $\mathrm{C}-\mathrm{H}$ oxidations, the $\mathrm{Fe}\left(\mathrm{N} 2 \mathrm{Py} 2-\mathrm{D}_{4}\right)$ complexes generally showed improved catalytic performances with respect to the corresponding $\mathrm{Fe}(\mathrm{N} 2 \mathrm{Py} 2)$ complexes, both in the sense of substrate conversion and of product yield. Accordingly, the question arises whether the $\mathrm{Fe}\left(\mathrm{N} 2 \mathrm{Py} 2-\mathrm{D}_{4}\right)$ complexes have a higher intrinsic reactivity or a longer lifetime compared to $\mathrm{Fe}(\mathrm{N} 2 \mathrm{Py} 2)$ complexes. To obtain insight into their kinetic behaviors, the reaction progression was monitored over time for a number of reactions.

Usingcis-cyclooctene (5) as the model substrate, catalytic epoxidation was carried out with $0.25 \mathrm{~mol} \%$ of either 1 or 1 $\mathbf{D}_{4}, 1.5 \mathrm{~mol} \% \mathrm{AcOH}$, and 1 equiv of $\mathrm{H}_{2} \mathrm{O}_{2}$ (added at once). As shown in Figure $7 \mathrm{a}, \mathbf{1}-\mathbf{D}_{4}$ consistently gave higher conversion and yield during the complete reaction duration to result in about 10 percentage units higher conversion and product yield. Interestingly, these two reactions showed very similar reaction rates and took about the same time to complete (around 40 min). In a similar manner, $\mathbf{2}-\mathbf{D}_{\mathbf{4}}$ showed a higher conversion and yield than 2 from an early stage of the reaction (Figure 

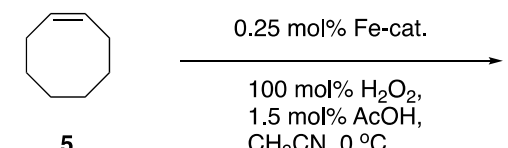

$\mathrm{CH}_{3} \mathrm{CN}, 0^{\circ} \mathrm{C}$
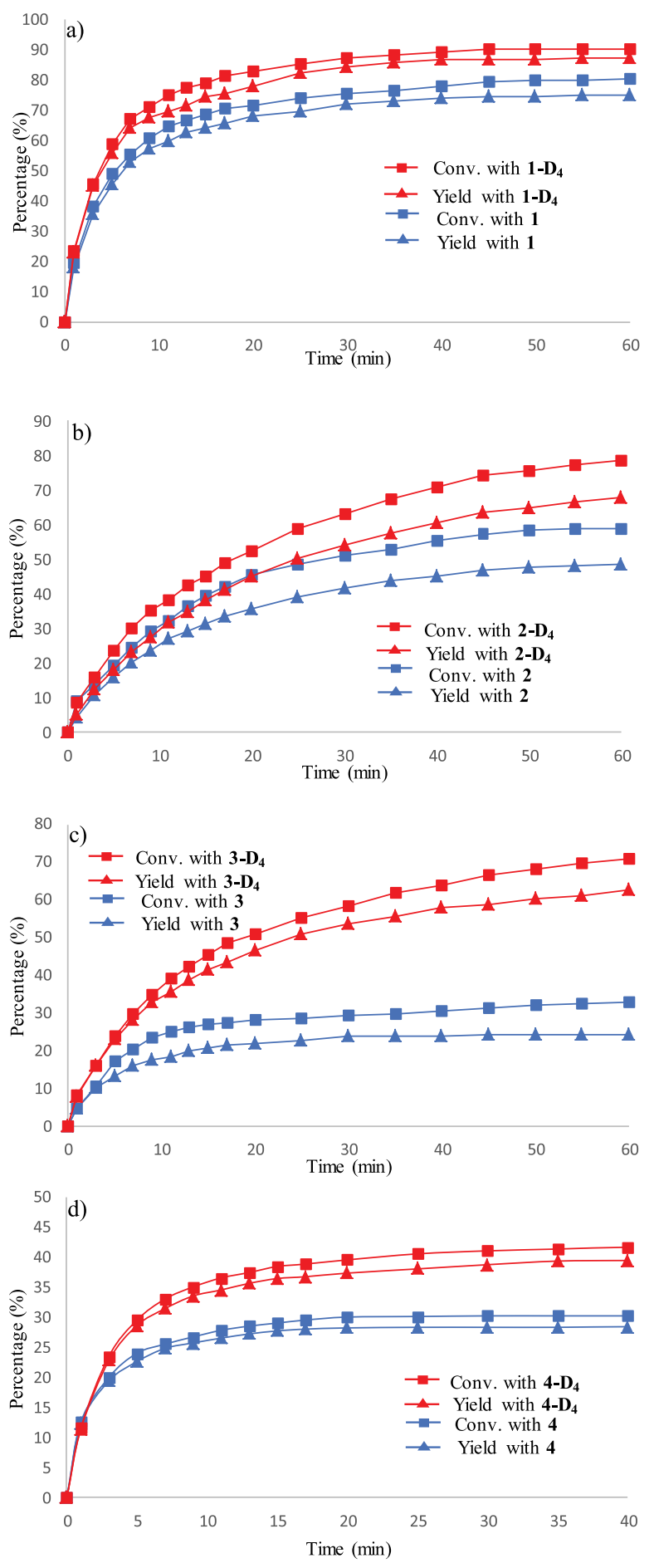

Figure 7. Time-dependent reaction profiles of the catalytic epoxidation of cis-cyclooctene (5) with catalysts $1-4$ vs catalysts 1-D $\mathrm{D}_{4}-4-\mathrm{D}_{4}$. Reaction conditions $(\mathrm{a}-\mathrm{c})$ : $\mathrm{Fe}$-cat.: $\mathrm{H}_{2} \mathrm{O}_{2}$ : substrate: $\mathrm{AcOH}=0.25: 100: 100: 1.5,0{ }^{\circ} \mathrm{C}$, the oxidant was added at once. Reaction conditions (d): Fe-cat.: $\mathrm{H}_{2} \mathrm{O}_{2}$ : substrate: $\mathrm{AcOH}=0.5$ : 100:100:1.5, $0{ }^{\circ} \mathrm{C}$, the oxidant was added at once. Yields and conversions were determined by GC analysis. 7b). More importantly, $\mathbf{2}-\mathbf{D}_{4}$ exhibited catalytic activity over a longer time frame. Consumption of 5 and formation of epoxide product 6 almost ceased around $50 \mathrm{~min}$ in the case of 2, while the reaction still occurred after $60 \mathrm{~min}$ with $2-\mathbf{D}_{4}$. Furthermore, the kinetic behavior of $3-\mathbf{D}_{4}$ was found to be dramatically different from that of 3 (Figure $7 \mathrm{c}$ ). While the reaction with 3 was observed to be complete after $30 \mathrm{~min}$, the catalytic conversion with $\mathbf{3}-\mathrm{D}_{4}$ continued after the observation period of $1 \mathrm{~h}$. This led to very different reaction results for 3 and $3-\mathrm{D}_{4}$ at $60 \mathrm{~min}$ (33\% vs $71 \%$ conversion, and $25 \%$ vs $63 \%$ yield, respectively). Since the reaction with $3-D_{4}$ seems to continue after $60 \mathrm{~min}$, the differences between these two catalysts can be even larger. In addition, the initial rate of the reaction was significantly different between 3 and $3-\mathrm{D}_{4}$ within the first $20 \mathrm{~min}$, the latter showing a higher initial rate. Finally, different durations of catalytic activity were also found in the reactions with 4 and $4-D_{4}$. In the case of 4 , the reaction was found to be complete after $20 \mathrm{~min}$, while catalytic conversion for the reaction with $4-\mathrm{D}_{4}$ was observed for at least $30 \mathrm{~min}$ (Figure $7 \mathrm{~d}$ ). Like for the reactions with $2-\mathrm{D}_{4}$ and $3-\mathbf{D}_{4}$, a significant increase in conversion and yield was found for $4-\mathrm{D}_{4}$ with respect to 4 , confirming the observations listed in Table 1.

In all these kinetic experiments, catalysts $1-D_{4}-4-D_{4}$ showed enhanced catalytic abilities compared to catalysts $\mathbf{1 - 4}$, which is in agreement with the observations described in Tables 1 and 2. Noticeable longer duration of catalytic activity in ciscyclooctene epoxidation was observed for catalysts $2-\mathrm{D}_{4}-\mathbf{4}-\mathrm{D}_{4}$, suggesting that these $\mathrm{Fe}\left(\mathrm{N} 2 \mathrm{Py} 2-\mathrm{D}_{4}\right)$ complexes have longer lifetimes than their $\mathrm{Fe}(\mathrm{N} 2 \mathrm{Py} 2)$ counterparts under catalytic conditions. Considering that the oxidant was added at once, the large initial amount of $\mathrm{H}_{2} \mathrm{O}_{2}$ in the reaction mixture will cause catalyst deactivation through ligand oxidation at a (relatively) early stage during the reaction, leading to decreasing concentrations of active $\mathrm{Fe}(\mathrm{N} 2 \mathrm{Py} 2)$ and $\mathrm{Fe}$ $\left(\mathrm{N} 2 \mathrm{Py} 2-\mathrm{D}_{4}\right)$ species in the reaction mixtures to different extents from the very beginning of the reaction.

In order to further evaluate the reactivities of these $\mathrm{Fe}(\mathrm{N} 2 \mathrm{Py} 2)$ and $\mathrm{Fe}\left(\mathrm{N} 2 \mathrm{Py} 2-\mathrm{D}_{4}\right)$ complexes, the reaction progression was monitored over time using a slow oxidant addition protocol typically used in non-heme oxidation catalysis (see above). Catalysts 3 and $\mathbf{3}-\mathbf{D}_{4}$ were used in this experiment since these showed the largest difference in catalytic results in the epoxidation of cis-cyclooctene. In these two experiments, 1.0 equiv of $\mathrm{H}_{2} \mathrm{O}_{2}$ was delivered by syringe pump over $30 \mathrm{~min}$. As clearly shown in Figure 8, 3 and $3-D_{4}$ provided nearly the same substrate conversions in the first $30 \mathrm{~min}$ of the reaction. Of note is that, during the addition of $\mathrm{H}_{2} \mathrm{O}_{2}$, conversions were always lower than the percentages of $\mathrm{H}_{2} \mathrm{O}_{2}$ added, suggesting that the amount of oxidant present was not a limiting factor. Beyond $30 \mathrm{~min}$, the conversion rate for 3 clearly started to drop with respect to that of $3-\mathbf{D}_{4}$, and at $55 \mathrm{~min}$, the reaction with 3 ceased; in contrast,cis-cyclooctene was still consumed until $70 \mathrm{~min}$ in the case of $\mathbf{3}-\mathbf{D}_{\mathbf{4}}$ (Figure 8). This observation is consistent with previous observations, again showing that $\mathbf{3}-\mathbf{D}_{\mathbf{4}}$ has a longer lifetime under catalytic conditions than 3 , which leads to higher substrate conversions and product yields. Because of the same reason, no obvious differences in product selectivities were found between the deuterated and nondeuterated catalysts (Tables 1 and 2).

This comparison indicates that the $\mathrm{Fe}(\mathrm{N} 2 \mathrm{Py} 2)$ and $\mathrm{Fe}\left(\mathrm{N} 2 \mathrm{Py} 2-\mathrm{D}_{4}\right)$ catalysts have the same (intrinsic) reactivity toward external substrates, which predominantly controls the reaction rate when catalyst decomposition is significantly 


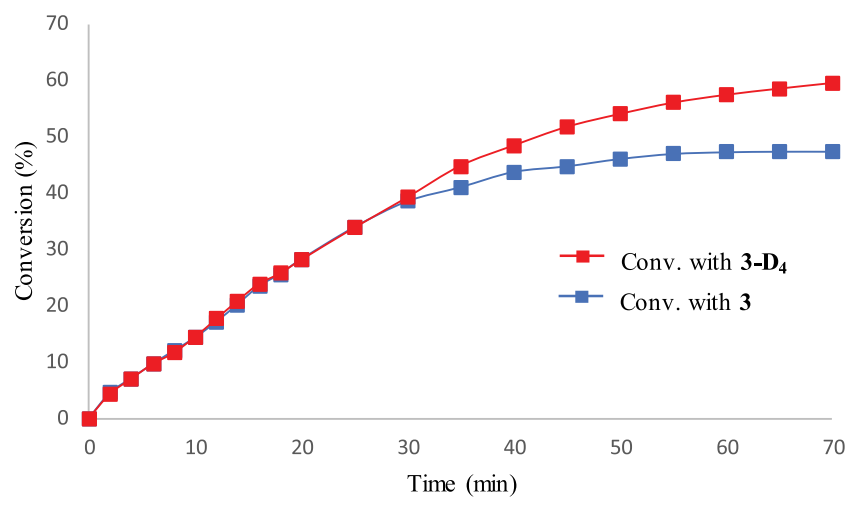

Figure 8. Reaction profiles of cis-cyclooctene (5) oxidation using catalyst 3 vs catalyst $3-\mathrm{D}_{4}$ with slow addition of the oxidant $(30 \mathrm{~min})$. Reaction conditions: Fe-cat.: $\mathrm{H}_{2} \mathrm{O}_{2}$ : substrate: $\mathrm{AcOH}=0.25$ : 100:100:1.5, $0{ }^{\circ} \mathrm{C}$, the oxidant was added by syringe pump over 30 min. Conversions are determined by GC analysis.

suppressed as is the case in the slow $\mathrm{H}_{2} \mathrm{O}_{2}$ addition protocol. In contrast, when the initial amount of oxidant is high, as is the case in the instant addition protocol, significantly different reaction profiles are obtained due to the different decomposition rates for $\mathbf{3}$ and $\mathbf{3}-\mathbf{D}_{\mathbf{4}}$ under these conditions. Figure 7 clearly shows that the improvements in catalytic outcomes and the extended lifetimes provided by the deuterated catalysts under these conditions are different from each other. $\mathbf{1}-\mathbf{D}_{4}$ showed a similar lifetime and a limited improvement in catalytic performance in comparison with 1 . Notably, the (initial) reaction rates observed for $\mathbf{1}$ and $\mathbf{1}-\mathbf{D}_{\mathbf{4}}$ are also similar.
As their reactivities toward substrate $\mathbf{5}$ are identical (vide supra), this indicates that $\mathbf{1}$ and $\mathbf{1}-\mathbf{D}_{\mathbf{4}}$ have similar (oxidative) robustness under the present conditions. In sharp contrast, 3$\mathbf{D}_{4}$ showed a much longer lifetime, a much higher initial reaction rate, and significantly improved catalytic outcomes than 3 in the epoxidation of cis-cyclooctene. The difference in the effect of ligand deuteration is likely due to the relatively high stability of the BPBP ligand under the oxidizing conditions, as a consequence of increased rigidity, with respect to the BPMEN ligand, which has a rather flexible bisalkylamine backbone. In this regard, $1-\mathrm{D}_{4}$ with deuterated 2pyridinylmethylene sites exhibits rather limited improvements compared to 1 .

This finding is in line with previous notions that the stability of non-heme iron catalysts under the oxidizing conditions has a strong correlation with ligand rigidity. ${ }^{8,9,22,49}$ It is believed that the enhanced robustness of the BPBP ligand is a key reason that (nondeuterated) BPBP-based iron complexes show better catalytic performances than their BPMEN-based counterparts. Deuteration of the BPMEN ligand results in catalytic performances of its iron complex $3-\mathrm{D}_{4}$ that are very similar to those of the nondeuterated BPBP-complex 1, which illustrates the importance of oxidative ligand decomposition on catalytic activity.

Ligand Oxidation of BPMEN-Based Iron Complexes. These observations of evidently different catalytic performances between 3 and $\mathbf{3}-\mathbf{D}_{4}$ triggered a more detailed investigation of the deactivation of BPMEN-based iron complexes. Similar to the decomposition test of BPBP-based iron complexes, 3 was mixed with 150 equiv of $\mathrm{H}_{2} \mathrm{O}_{2}$ and 50

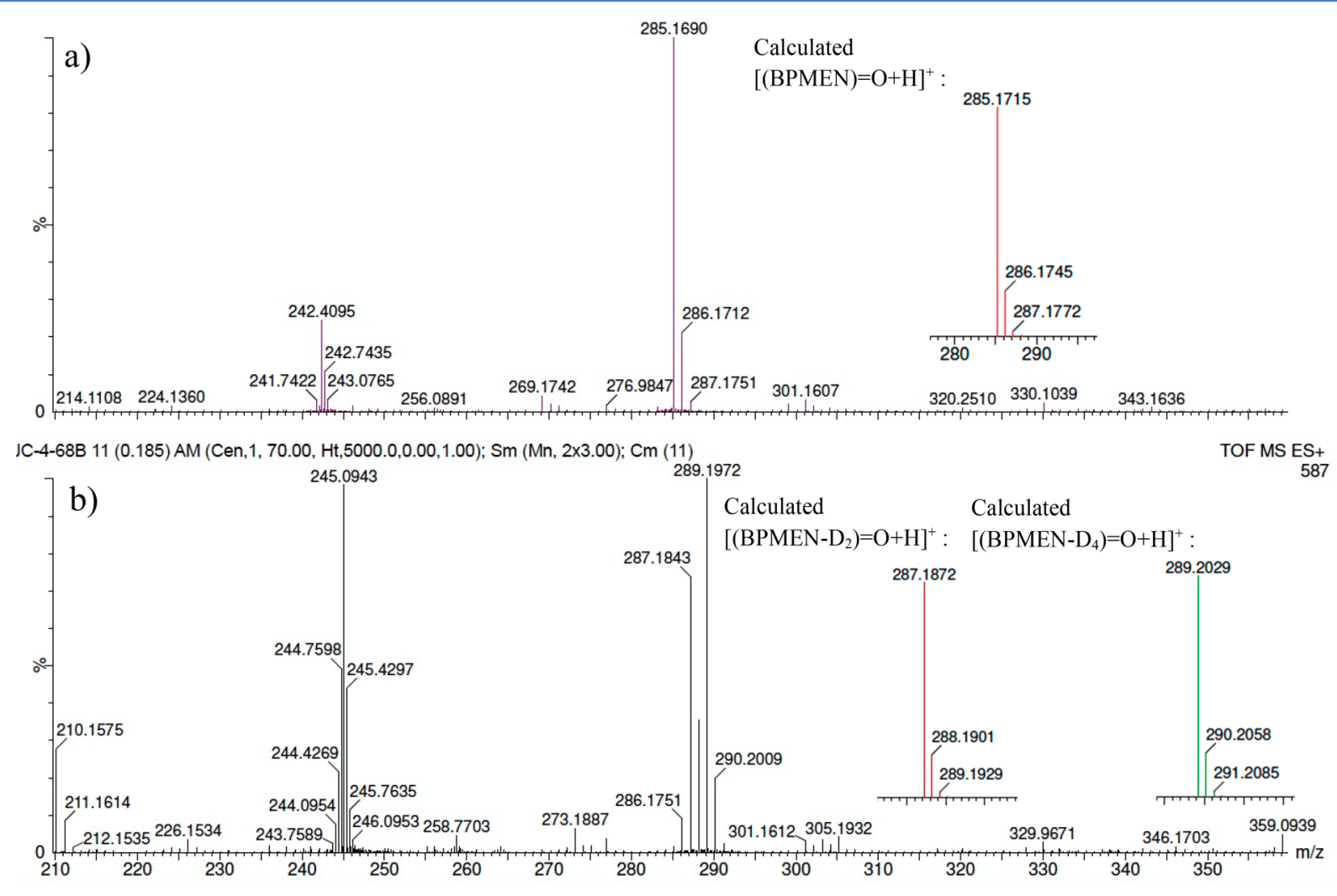

Figure 9. ESI-MS of the reaction of $3(\mathrm{a})$ or $3-\mathrm{D}_{4}(\mathrm{~b})(2 \mathrm{mM})$ with $\mathrm{H}_{2} \mathrm{O}_{2}$ (150 equiv) and $\mathrm{AcOH}$ (50 equiv) in $\mathrm{MeCN}$, stirred at $0{ }^{\circ} \mathrm{C}$ for 10 min. ESI-MS was directly measured from the reaction mixture without any workup. a): The peak at $m / z=285.1690$ corresponds to (BPMEN)=O. b): The peak at $m / z=287.1843$ corresponds to $(\text { BPMEN-D })_{2}=\mathrm{O}$. The peak at $m / z=289.1972$ corresponds to $\left(\right.$ BPMEN-D $\left._{4}\right)=\mathrm{O}$. The peaks at $m / z$ $=288$ and 286 are due to the presence of incompletely deuterated complex $3-\mathrm{D}_{3}$. 
equiv of $\mathrm{AcOH}$ in $\mathrm{MeCN}$. After the mixture was stirred at $0{ }^{\circ} \mathrm{C}$ for $10 \mathrm{~min}$, similar to the observation for 1 , ESI-MS of the resulting mixture revealed a major peak at $\mathrm{m} / z=285.1690$, with an isotopic pattern that is in agreement with a carbonyl compound $(\mathrm{BPMEN})=\mathrm{O}($ calcd $m / z=285.1715)$ derived from aliphatic $\mathrm{C}-\mathrm{H}$ oxidation of the ligand (Figure 9a). Interestingly, the same oxidation protocol applied to $3-\mathrm{D}_{4}$ gave two signals in this $m / z$ region, that is, at $m / z=287.1843$ and 289.1972 (Figure 9b), indicating that $\mathrm{C}-\mathrm{H}$ oxidation happened both at one of the 2-pyridinylmethylene positions (calcd $m / z$ for $\left[\left(\mathrm{BPMEN}_{-} \mathrm{D}_{2}\right)=\mathrm{O}+\mathrm{H}\right]^{+}$is 287.1872 , Figure $9 \mathrm{~b}$, inset) and at one of the methylene sites of the bisalkylamine backbone $\left(\right.$ calcd $m / z$ for $\left[\left(\text { BPMEN-D }_{4}\right)=\mathrm{O}+\mathrm{H}\right]^{+}$ is 289.2029, Figure 9b, inset). While BDE arguments would justify that oxidation takes place at the ligand backbone, we cannot completely rule out that oxidation (partly) takes place at an $\mathrm{N}$-methyl site. This observation indicates that ligand oxidation in 3 and $3-D_{4}$ is not restricted to the 2 pyridinylmethylene sites as observed for the other complexes discussed here, but may also occur on the bis-alkylamine backbone in the BPMEN ligand. Installation of deuterium atoms on the 2-pyridinylmethylene positions possibly shifts $\mathrm{C}-\mathrm{H}$ oxidation more to methylene sites of the ligand backbone in $3-D_{4}$. However, the oxidation of these methylene sites seems to be more sluggish, leading to a slower deactivation process of $3-\mathrm{D}_{4}$ compared to 3 , and resulting in enhanced robustness and a much longer lifetime of $3-\mathbf{D}_{4}$. In addition, oxidatively dimerized species were also found in both cases, i.e., the signal at $m / z=242.4095$ corresponds to $\left[\mathrm{Fe}_{2}(\mu\right.$ O) $\left.(\text { BPMEN })_{2}(\mathrm{OAc})\right]^{3+}$ (Figure 9a, calcd 242.4151) and the signal at $m / z=245.0943$ corresponds to $\left[\mathrm{Fe}_{2}(\mu\right.$-O) (BPMEN$\left.\left.\mathrm{D}_{4}\right)_{2}(\mathrm{OAc})\right]^{3+}$ (Figure 9b, calcd 245.0985).

\section{CONCLUSIONS}

The present work demonstrates that the lifetimes of $\mathrm{Fe}$ (N2Py2)-based oxidation catalysts can be enhanced by replacing the $\mathrm{H}$ atoms with $\mathrm{D}$ atoms in the 2-pyridinylmethylene sites of the N2Py2 ligands. As a result, improved substrate conversions and product yields are consistently obtained in both catalytic aliphatic $\mathrm{C}-\mathrm{H}$ oxidations and alkene epoxidations. This slight manipulation of the ligand is actually able to double the conversion and yield in particular catalytic reactions, and it dramatically increase the lifetimes of the catalysts depending on the overall structure of the N2Py2 ligand. The $\mathrm{Fe}(\mathrm{N} 2 \mathrm{Py} 2)$ and $\mathrm{Fe}\left(\mathrm{N} 2 \mathrm{Py} 2-\mathrm{D}_{4}\right)$ catalysts show identical intrinsic reactivities (as illustrated in reaction kinetics) and similar product selectivities (as shown in catalytic performance), which is attributed to unchanged electronic and steric properties of the deuterated and nondeuterated ligands. The overall effect of ligand deuteration on catalyst performance is exemplified by the similar catalytic performance of the deuterated BPMEN-catalyst $3-\mathbf{D}_{4}$ compared to nondeuterated BPBP-catalyst $\mathbf{1}$.

This ligand design strategy has wide applicability as evaluated for a series of N2Py2 ligands with variations on both the bis-alkylamine and pyridine fragments. Yet, the improvements in catalytic performances and lifetimes provided by the deuterated ligands are different and are more pronounced for ligands with a more flexible bis-alkylamine backbone, which is likely due to differences in the inherent robustness of the parent N2Py2 ligands. The success of nonheme iron oxidation catalysts based on ligands containing more rigid bis-alkylamine backbones, with the BPBP ligand as a prominent example, has been explained in terms of the stronger and more rigid chelate provided by these ligands, which would prevent (oxidative) leaching of iron. 8,9 Our current findings suggest that a more rigid ligand manifold attenuates intramolecular ligand oxidation, which would lead to catalyst decomposition, through a more restricted approach of the 2-pyridinylmethylene $\mathrm{C}-\mathrm{H}$ bonds to the intermediate iron-oxo moiety. Accordingly, deuteration of the 2-pyridinylmethylene sites in more flexible ligands, such as BPMEN, results in a dramatic increase in overall catalytic performance because of less facile ligand oxidation and concomitant catalyst decomposition. The present study highlights the sensitivity of the 2-pyridinylmethylene positions in N2Py2 ligands under oxidizing conditions, and provides an additional tool for the development of more robust molecular catalysts for oxidation reactions.

\section{ASSOCIATED CONTENT}

\section{Supporting Information}

The Supporting Information is available free of charge on the ACS Publications website at DOI: 10.1021/acscatal.8b04463.

Experimental details and NMR data (PDF)

\section{AUTHOR INFORMATION}

\section{Corresponding Author}

*E-mail: r.j.m.kleingebbink@uu.nl.

ORCID $\odot$

Robertus J. M. Klein Gebbink: 0000-0002-0175-8302

Notes

The authors declare no competing financial interest.

\section{ACKNOWLEDGMENTS}

J.C. acknowledges the China Scholarship Council (CSC) for a doctoral scholarship.

\section{REFERENCES}

(1) Olivo, G.; Cussó, O.; Costas, M. Biologically Inspired C-H and $\mathrm{C}=\mathrm{C}$ Oxidations with Hydrogen Peroxide Catalyzed by Iron Coordination Complexes. Chem. - Asian J. 2016, 11, 3148-3158.

(2) Oloo, W. N.; Que, L., Jr. Bioinspired Nonheme Iron Catalysts for $\mathrm{C}-\mathrm{H}$ and $\mathrm{C}=\mathrm{C}$ Bond Oxidation: Insights into the Nature of the Metal-Based Oxidants. Acc. Chem. Res. 2015, 48, 2612-2621.

(3) Bryliakov, K. P.; Talsi, E. P. Active Sites and Mechanisms of Bioinspired Oxidation with $\mathrm{H}_{2} \mathrm{O}_{2}$ Catalyzed by Non-Heme Fe and Related Mn Complexes. Coord. Chem. Rev. 2014, 276, 73-96.

(4) Engelmann, X.; Monte-Pérez, I.; Ray, K. Oxidation Reactions with Bioinspired Mononuclear Non-Heme Metal-Oxo Complexes. Angew. Chem., Int. Ed. 2016, 55, 7632-7649.

(5) Milan, M.; Salamone, M.; Costas, M.; Bietti, M. The Quest for Selectivity in Hydrogen Atom Transfer Based Aliphatic C-H Bond Oxygenation. Acc. Chem. Res. 2018, 51, 1984-1995.

(6) Sacramento, J. J. D.; Goldberg, D. P. Factors Affecting Hydrogen Atom Transfer Reactivity of Metal-Oxo Porphyrinoid Complexes. Acc. Chem. Res. 2018, 51, 2641-2652.

(7) Nam, W.; Lee, Y.-M.; Fukuzumi, S. Hydrogen Atom Transfer Reactions of Mononuclear Nonheme Metal-Oxygen Intermediates. Acc. Chem. Res. 2018, 51, 2014-2022.

(8) England, J.; Davies, C. R.; Banaru, M.; White, A. J. P.; Britovsek, G. J. P. Catalyst Stability Determines the Catalytic Activity of NonHeme Iron Catalysts in the Oxidation of Alkanes. Adv. Synth. Catal. 2008, 350, 883-897.

(9) Grau, M.; Kyriacou, A.; Cabedo Martinez, F.; de Wispelaere, I. M.; White, A. J. P.; Britovsek, G. J. P. Unraveling the Origins of 
Catalyst Degradation in Non-Heme Iron-Based Alkane Oxidation. Dalton Trans. 2014, 43, 17108-17119.

(10) Ryu, J. Y.; Kim, J.; Costas, M.; Chen, K.; Nam, W.; Que, L., Jr. High Conversion of Olefins to cis-Diols by Non-Heme Iron Catalysts and $\mathrm{H}_{2} \mathrm{O}_{2}$. Chem. Commun. 2002, 0, 1288-1289.

(11) White, M. C.; Doyle, A. G.; Jacobsen, E. N. A Synthetically Useful, Self-Assembling MMO Mimic System for Catalytic Alkene Epoxidation with Aqueous $\mathrm{H}_{2} \mathrm{O}_{2}$. J. Am. Chem. Soc. 2001, 123, 71947195.

(12) Gómez, L.; Garcia-Bosch, I.; Company, A.; Benet-Buchholz, J.; Polo, A.; Sala, X.; Ribas, X.; Costas, M. Stereospecific C-H Oxidation with $\mathrm{H}_{2} \mathrm{O}_{2}$ Catalyzed by a Chemically Robust Site Isolated Iron Catalyst. Angew. Chem., Int. Ed. 2009, 48, 5720-5723.

(13) Gómez, L.; Canta, M.; Font, D.; Prat, I.; Ribas, X.; Costas, M. Regioselective Oxidation of Nonactivated Alkyl C-H Groups Using Highly Structured Non-Heme Iron Catalysts. J. Org. Chem. 2013, 78, $1421-1433$.

(14) Vermeulen, N. A.; Chen, M. S.; White, M. C. The Fe(PDP)Catalyzed Aliphatic C-H Oxidation: a Slow Addition Protocol. Tetrahedron 2009, 65, 3078-3084.

(15) Yazerski, V.; Spannring, P.; Gatineau, D.; Woerde, C. H. M.; Wieclawska, S. M.; Lutz, M.; Kleijn, H.; Klein Gebbink, R. J. M. Making $\mathrm{Fe}(\mathrm{BPBP})$-Catalyzed $\mathrm{C}-\mathrm{H}$ and $\mathrm{C}=\mathrm{C}$ Oxidations More Affordable. Org. Biomol. Chem. 2014, 12, 2062-2070.

(16) Cussó, O.; Garcia-Bosch, I.; Ribas, X.; Lloret-Fillol, J.; Costas, M. Asymmetric Epoxidation with $\mathrm{H}_{2} \mathrm{O}_{2}$ by Manipulating the Electronic Properties of Non-Heme Iron Catalysts. J. Am. Chem. Soc. 2013, 135, 14871-14878.

(17) Cussó, O.; Ribas, X.; Lloret-Fillol, J.; Costas, M. Synergistic Interplay of a Non-Heme Iron Catalyst and Amino Acid Coligands in $\mathrm{H}_{2} \mathrm{O}_{2}$ Activation for Asymmetric Epoxidation of $\alpha$-Alkyl-Substituted Styrenes. Angew. Chem., Int. Ed. 2015, 54, 2729-2733.

(18) Suzuki, K.; Oldenburg, P. D.; Que, L., Jr. Iron-Catalyzed Asymmetric Olefin cis-Dihydroxylation with 97\% Enantiomeric Excess. Angew. Chem., Int. Ed. 2008, 47, 1887-1889.

(19) Cussó, O.; Cianfanelli, M.; Ribas, X.; Klein Gebbink, R. J. M.; Costas, M. Iron Catalyzed Highly Enantioselective Epoxidation of Cyclic Aliphatic Enones with Aqueous $\mathrm{H}_{2} \mathrm{O}_{2}$. J. Am. Chem. Soc. 2016, 138, 2732-2738.

(20) Font, D.; Canta, M.; Milan, M.; Cussó, O.; Ribas, X.; Klein Gebbink, R. J. M.; Costas, M. Readily Accessible Bulky Iron Catalysts Exhibiting Site Selectivity in the Oxidation of Steroidal Substrates. Angew. Chem., Int. Ed. 2016, 55, 5776-5779.

(21) Zima, A. M.; Lyakin, O. Y.; Ottenbacher, R. V.; Bryliakov, K. P.; Talsi, E. P. Dramatic Effect of Carboxylic Acid on the Electronic Structure of the Active Species in Fe(PDP)-Catalyzed Asymmetric Epoxidation. ACS Catal. 2016, 6, 5399-5404.

(22) Chen, M. S.; White, M. C. A Predictably Selective Aliphatic CH Oxidation Reaction for Complex Molecule Synthesis. Science 2007, 318, 783-787.

(23) Chen, M. S.; White, M. C. Combined Effects on Selectivity in Fe-Catalyzed Methylene Oxidation. Science 2010, 327, 566-571.

(24) Gormisky, P. E.; White, M. C. Catalyst-Controlled Aliphatic $\mathrm{C}-\mathrm{H}$ Oxidations with a Predictive Model for Site-Selectivity. J. Am. Chem. Soc. 2013, 135, 14052-14055.

(25) Howell, J. M.; Feng, K.; Clark, J. R.; Trzepkowski, L. J.; White, M. C. Remote Oxidation of Aliphatic $\mathrm{C}-\mathrm{H}$ Bonds in NitrogenContaining Molecules. J. Am. Chem. Soc. 2015, 137, 14590-14593.

(26) Osberger, T. J.; Rogness, D. C.; Kohrt, J. T.; Stepan, A. F.; White, M. C. Oxidative Diversification of Amino Acids and Peptides by Small-Molecule Iron Catalysis. Nature 2016, 537, 214-219.

(27) Canta, M.; Font, D.; Gõmez, L.; Ribas, X.; Costas, M. The Iron(II) Complex $\left[\mathrm{Fe}\left(\mathrm{CF}_{3} \mathrm{SO}_{3}\right)_{2}(\mathrm{mcp})\right]$ as a Convenient, Readily Available Catalyst for the Selective Oxidation of Methylenic Sites in Alkanes. Adv. Synth. Catal. 2014, 356, 818-830.

(28) Thibon, A.; Bartoli, J.-F.; Bourcier, S.; Banse, F. Mononuclear Iron Complexes Relevant to Nonheme Iron Oxygenases. Synthesis, Characterizations and Reactivity of Fe-Oxo and Fe-Peroxo Intermediates. Dalton Trans. 2009, 0, 9587-9594.
(29) White, M. C.; Zhao, J. Aliphatic C-H Oxidations for LateStage Functionalization. J. Am. Chem. Soc. 2018, 140, 13988-14009.

(30) Chen, J.; Lutz, M.; Milan, M.; Costas, M.; Otte, M.; Klein Gebbink, R. J. M. Non-Heme Iron Catalysts with a Rigid BisIsoindoline Backbone and Their Use in Selective Aliphatic $\mathrm{C}-\mathrm{H}$ Oxidation. Adv. Synth. Catal. 2017, 359, 2590-2595.

(31) Lange, S. J.; Miyake, H.; Que, L., Jr. Evidence for a Nonheme $\mathrm{Fe}(\mathrm{IV})=\mathrm{O}$ Species in the Intramolecular Hydroxylation of a Phenyl Moiety. J. Am. Chem. Soc. 1999, 121, 6330-6331.

(32) Mekmouche, Y.; Ménage, S.; Toia-Duboc, C.; Fontecave, M.; Galey, J.-B.; Lebrun, C.; Pécaut, J. $\mathrm{H}_{2} \mathrm{O}_{2}$-Dependent Fe-Catalyzed Oxidations: Control of the Active Species. Angew. Chem., Int. Ed. 2001, 40, 949-952.

(33) Nielsen, A.; Larsen, F. B.; Bond, A. D.; McKenzie, C. J. Regiospecific Ligand Oxygenation in Iron Complexes of a Carboxylate-Containing Ligand Mediated by a Proposed $\mathrm{Fe}^{\mathrm{V}}-\mathrm{Oxo}$ Species. Angew. Chem., Int. Ed. 2006, 45, 1602-1606.

(34) Bukowski, M. R.; Zhu, S.; Koehntop, K. D.; Brennessel, W. W.; Que, L., Jr. Characterization of an $\mathrm{Fe}^{\mathrm{III}}-\mathrm{OOH}$ Species and Its Decomposition Product in a Bleomycin Model System. JBIC, J. Biol. Inorg. Chem. 2004, 9, 39-48.

(35) You, L.; Long, S. R.; Lynch, V. M.; Anslyn, E. V. Dynamic Multicomponent Hemiaminal Assembly. Chem. - Eur. J. 2011, 17, 11017-11023.

(36) Lee, D.; Lippard, S. J. Oxidative N-Dealkylation of a Carboxylate-Bridged Diiron(II) Precursor Complex by Reaction with $\mathrm{O}_{2}$ Affords the Elusive $\left\{\mathrm{Fe}_{2}(\mu-\mathrm{OH})_{2}\left(\mu-\mathrm{O}_{2} \mathrm{CR}\right)\right\}^{3+}$ Core of Soluble Methane Monooxygenase Hydroxylase. J. Am. Chem. Soc. 2001, 123, 4611-4612.

(37) Lee, D.; Lippard, S. J. Synthetic Analogue of the $\left\{\mathrm{Fe}_{2}(\mu\right.$ $\left.\mathrm{OH})_{2}\left(\mu-\mathrm{O}_{2} \mathrm{CR}\right)\right\}^{3+}$ Core of Soluble Methane Monooxygenase Hydroxylase via Synthesis and Dioxygen Reactivity of CarboxylateBridged Diiron(II) Complexes. Inorg. Chem. 2002, 41, 827-837.

(38) Carson, E. C.; Lippard, S. J. Synthesis and Oxidation of Carboxylate-Bridged Diiron(II) Complexes with Substrates Tethered to Primary Alkyl Amine Ligands. J. Inorg. Biochem. 2006, 100, 11091117.

(39) Groni, S.; Dorlet, P.; Blain, G.; Bourcier, S.; Guillot, R.; Anxolabéhère-Mallart, E. Reactivity of an Aminopyridine $\left[\mathrm{LMn}^{\mathrm{II}}\right]^{2+}$ Complex with $\mathrm{H}_{2} \mathrm{O}_{2}$ Detection of Intermediates at Low Temperature. Inorg. Chem. 2008, 47, 3166-3172.

(40) Pijper, D.; Saisaha, P.; De Boer, J. W.; Hoen, R.; Smit, C.; Meetsma, A.; Hage, R.; Van Summeren, R. P.; Alsters, P. L.; Feringa, B. L.; Browne, W. R. The Unexpected Role of Pyridine-2-carboxylic Acid in Manganese Based Oxidation Catalysis with Pyridin-2-yl Based Ligands. Dalton Trans. 2010, 39, 10375-10381.

(41) Vad, M. S.; Nielsen, A.; Lennartson, A.; Bond, A. D.; McGrady, J. E.; McKenzie, C. J. Switching on Oxygen Activation by Cobalt Complexes of Pentadentate Ligands. Dalton Trans. 2011, 40, 1069810707.

(42) Lonnon, D. G.; Craig, D. C.; Colbran, S. B. An Unusual but Informative Synthesis and the Crystal Structure of $\left[\mathrm{Co}\left(\mathrm{tpaCO}_{2}\right) \mathrm{Cl}\right]$ $\left(\mathrm{ClO}_{4}\right) \quad\left(\mathrm{tpaCO}_{2}{ }^{-}=6\right.$-carboxylato-2 $-($ pyridylmethyl $)$-bis $(2$ pyridylmethyl)amine). Inorg. Chem. Commun. 2003, 6, 1351-1353.

(43) Seregin, I. V.; Schammel, A. W.; Gevorgyan, V. Base- and Ligand-free Room-Temperature Synthesis of N-Fused Heteroaromatic Compounds via the Transition Metal-Catalyzed Cycloisomerization Protocol. Org. Lett. 2007, 9, 3433-3436.

(44) Rüger, N.; Roatsch, M.; Emmrich, T.; Franz, H.; Schüle, R.; Jung, M.; Link, A. Tetrazolylhydrazides as Selective Fragment-Like Inhibitors of the JumonjiC-Domain-Containing Histone Demethylase KDM4A. ChemMedChem 2015, 10, 1875-1883.

(45) Costas, M.; Tipton, A. K.; Chen, K.; Jo, D. H.; Que, L., Jr. Modeling Rieske Dioxygenases: The First Example of Iron-Catalyzed Asymmetric cis-Dihydroxylation of Olefins. J. Am. Chem. Soc. 2001, 123, 6722-6723.

(46) Chen, K.; Que, L., Jr. Evidence for the Participation of a HighValent Iron-Oxo Species in Stereospecific Alkane Hydroxylation by a Non-Heme Iron Catalyst. Chem. Commun. 1999, 1375-1376. 
(47) During the preparation of the revised manuscript, Costas and co-workers reported on the synthesis of complex $2-\mathrm{D}_{4}$ and its use in water oxidation catalysis. Related ligand degradation pathways and beneficial effects on catalysis were observed as those described here. See: Codolà, Z.; Gamba, I.; Acuña-Parés, F.; Casadevall, C.; Clémancey, M.; Latour, J.-M.; Luis, J. M.; Lloret-Fillol, J.; Costas, M. Design of Iron Coordination Complexes as Highly Active Homogenous Water Oxidation Catalysts by Deuteration of Oxidation-Sensitive Sites. J. Am. Chem. Soc. 2019, 141, 323-333.

(48) Costas, M.; Que, L., Jr. Ligand Topology Tuning of IronCatalyzed Hydrocarbon Oxidations. Angew. Chem., Int. Ed. 2002, 41, 2179-2181.

(49) England, J.; Britovsek, G. J. P.; Rabadia, N.; White, A. J. P. Ligand Topology Variations and the Importance of Ligand Field Strength in Non-Heme Iron Catalyzed Oxidations of Alkanes. Inorg. Chem. 2007, 46, 3752-3767. 